\title{
Synthesis and Biological Evaluation of 2-Heteroarylthioalkanoic Acid Analogues of Clofibric Acid as Peroxisome Proliferator-Activated Receptor $\alpha$ Agonists
}

\author{
Letizia Giampietro, ${ }^{\dagger}$ Alessandra Ammazzalorso, ${ }^{\dagger}$ Antonella Giancristofaro, ${ }^{\dagger}$ Fabio Lannutti, ${ }^{\dagger}$ Giancarlo Bettoni, ${ }^{\dagger}$ \\ Barbara De Filippis, ${ }^{\dagger}$ Marialuigia Fantacuzzi ${ }^{\dagger}$ Cristina Maccallini ${ }^{\dagger}$ Michele Petruzzelli, ${ }^{\star} \S$ Annalisa Morgano, \\ Antonio Moschetta, ${ }^{\dagger}$, and Rosa Amoroso* ${ }^{\dagger} \dagger$ \\ ${ }^{\dagger}$ Dipartimento di Scienze del Farmaco, Università degli Studi “G. d'Annunzio”, Chieti, Italy, "Dipartimento di Farmacologia Traslazionale, \\ Consorzio Mario Negri Sud, Santa Maria Imbaro (CH), Italy, ${ }^{\S}$ Dipartimento di Medicina Interna e Medicina Pubblica, \\ Clinica Medica "A. Murri”, Università di Bari, Bari, Italy, and" Unità di Patologia Molecolare e Genomica, \\ Centro Scienze dell'Invecchiamento (CeSI), Fondazione Università “G. d'Annunzio”, Chieti, Italy
}

Received May 30, 2009

A series of 2-heteroarylthioalkanoic acids were synthesized through systematic structural modifications of clofibric acid and evaluated for human peroxisome proliferator-activated receptor $\alpha$ (PPAR $\alpha)$ transactivation activity, with the aim of obtaining new hypolipidemic compounds. Some thiophene and benzothiazole derivatives showing a good activation of the receptor $\alpha$ were screened for activity against the PPAR $\gamma$ isoform. The gene induction of selected compounds was also investigated in the human hepatoma cell line.

\section{Introduction}

The nuclear peroxisome proliferator-activated receptors $\left(\right.$ PPARs $\left.^{a}\right)$ are ligand-dependent transcription factors belonging to the nuclear receptor superfamily. ${ }^{1}$ Upon ligand binding, PPARs heterodimerize with the retinoid X receptor (RXR) and regulate target gene transcription at specific consensus DNA sequences, the peroxisome proliferator response elements (PPRE) ${ }^{2}$ Three subtypes of PPARs (PPAR $\alpha$, PPAR $\gamma$, and PPAR $\delta$ ) have been identified to date. Their endogenous ligands include fatty acids and eicosanoids. ${ }^{3}$ PPAR $\alpha$ is predominantly expressed in liver, where it plays a critical role in lipid homeostasis by regulating fatty acid binding, uptake, and oxidation. ${ }^{4}$ It is also expressed in a variety of cell types, including smooth muscle cells, endothelial cells, and macrophages, playing a pivotal role in processes such as atherosclerosis and inflammation. ${ }^{5}$

Several studies have analyzed the overall contribution of PPAR $\alpha$ to cardiovascular disease, and a large number of synthetic activators with atheroprotective properties in humans have been described. ${ }^{6}$ Fibrates are the only marketed PPAR $\alpha$ agonists that are effective in lowering elevated serum triglyceride levels and moderately raising high-density lipoproteins (HDL). Their chemical structures are characterized by the presence of the 2-phenoxy-2-methylpropanoic moiety. Fibrates have weak affinities to both rodent and human cloned receptors, with extremely poor subtype selectivity, ${ }^{7}$

*To whom correspondence should be addressed. Phone: +390871 3554686. Fax: +390871 3554911. E-mail: ramoroso@unich.it.

${ }^{a}$ Abbreviations: PPARs, peroxisome proliferator-activated receptors; RXR, retinoid X receptor; PPRE, peroxisome proliferator response elements; HDL, high-density lipoproteins; CPT1A, carnitine palmitoyl transferase 1A; HepG2, human hepatocellular liver carcinoma cell line; RTqPCR, real-time quantitative polymerase chain reaction; HEK293, human embryonic kidney 293 cell line; FBS-GOLD, fetal bovine serum "GOLD".

pubs.acs.org/jmc

Published on Web 09/30/2009 and necessitate use of high micromolar concentrations to activate human PPAR $\alpha(30-55 \mu \mathrm{M})$. Recent advances in nuclear receptor ligand discovery have led to the identification of a second generation PPAR $\alpha$ agonists with affinities for activation in the nanomolar range compared to the micromolar range for the fibrates. Examples are the ureido-based fibric acid $\mathrm{GW} 7647^{8}(\mathbf{1})$, the phenylpropanoic acid derivative KCL19980010799 (2), the fibrate LY518674 ${ }^{10}$ (3), the 2,3dihydrobenzofuran-2-carboxylic acids ${ }^{11} 4$, which are constrained analogues of fibric acid, the indaneureidothioisobutyric acids ${ }^{12} \mathbf{5}$, and the 1,3-dioxane-2-carboxylic acids ${ }^{13} \mathbf{6}$ (Figure 1).

In this study, we aimed to optimize the PPAR $\alpha$ binding profile and the in vitro efficacy of classical fibrates by synthesizing a series of new compounds derived from chemical modifications of clofibric acid (7), the active metabolite of clofibrate (Figure 2). The clofibric acid moiety was changed by substituting the oxygen with sulfur, thus leading to thioalkanoic acids. A previous example of this modification is the potent and selective PPAR $\alpha$ agonist $1{ }^{8}$ Moreover, the phenyl ring was replaced with the heterocyclic scaffolds thiophene, pyridine, and benzothiazole, with different substitution patterns. In some compounds a chiral center was introduced in $\alpha$-position to the carboxylic group. For reference compounds in the pharmacological evaluations, we selected compounds 7 and 1 . On the basis of in vitro PPAR $\alpha$ transactivation assay results, some compounds were also tested on PPAR $\gamma$ and were selected for the in vitro analysis of target gene expression.

\section{Chemistry}

Compounds 8, 9a,b, and $\mathbf{1 2 a}-\mathbf{u}$ (Table 1) were easily obtained in good yields by standard esterification procedures followed by hydrolysis. We have previously described the synthesis of $\mathbf{8}, \mathbf{9 a}, \mathbf{b}$, and $\mathbf{1 2 a}, \mathbf{b}$, which were found to have interesting antiplatelet properties. ${ }^{14}$ Esters $11 \mathbf{c}-\mathbf{u}$ were obtained 


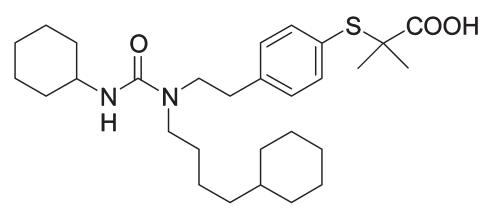

1 (GW7647)

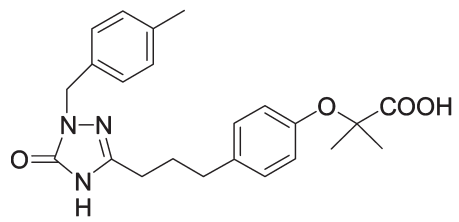

3 (LY518674)

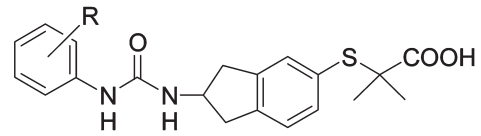

5<smiles>CC[C@H](Cc1ccc(OC)c(C(=O)NCc2ccc(C(F)(F)F)cc2)c1)C(=O)O</smiles>

2 (KCL1998001079)<smiles>[R]c1ccc(OCCCOc2ccc3c(c2)CC([R7])(C(=O)O)O3)c([R2])c1</smiles>

4

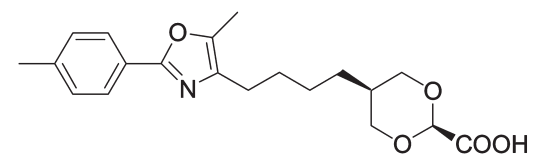

6 (NS220)

Figure 1. Selective PPAR $\alpha$ agonists.

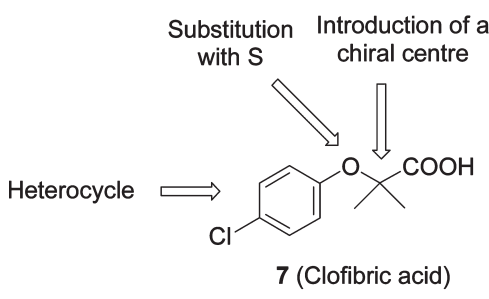

Figure 2. Structural modifications of clofibric acid.

by $S_{N} 2$ reaction of 2 -mercaptoheterocycles $(\mathbf{1 0 c}-\mathbf{u})$ with proper 2-bromoesters, in the presence of sodium in absolute ethanol at reflux. The basic hydrolysis by $1 \mathrm{~N} \mathrm{NaOH}$ of $\mathbf{1 1 c}-\mathbf{u}$ gave the acids $12 \mathbf{c}-\mathbf{u}$. When not commercially available, substituted 2-mercaptobenzothiazoles were synthesized according to well established procedures. ${ }^{15}$ The $r a c-12 l$ and $r a c-120$ acids were also synthesized in enantiomerically pure form. In this case, we started from optically active $(R)$ - and $(S)$-2-bromoacids, esterified with ethanol, toluene, and concentrated sulfuric acid in a Dean-Stark apparatus to obtain the corresponding bromoesters, which were used for $\mathrm{S}_{\mathrm{N}} 2$ reaction with 2-mercaptoheterocycles $\mathbf{1 0 l}$ and $\mathbf{1 0 0}$ to give $(R)$ - and $(S)$-111 and $(R)$ - and $(S)$ 11o. Finally, the optically pure $(R)$ - and $(S)$-12l and $(R)$ - and $(S)$-120 acids were obtained by hydrolysis with $6 \mathrm{~N} \mathrm{HCl}$ (Scheme 1).

\section{Results and Discussion}

With the aim of identifying new compounds able to activate the PPAR $\alpha$ receptor, $\mathbf{8}, \mathbf{9 a}, \mathbf{b}$, and $r a c-\mathbf{1 2} \mathbf{a}-\mathbf{u}$ were evaluated for human PPAR $\alpha$ functional activity by a cell-based transactivation assay in eukaryotic cells, ${ }^{16}$ a powerful and widely used method whose good correlation with in vivo activity is generally accepted. First, we evaluated the activity of new compounds at a concentration of $150 \mu \mathrm{M}$, with $7(150 \mu \mathrm{M})$ and $1(1 \mu \mathrm{M})$ as reference compounds; results are expressed as fold activation. Then the compounds with the best activity

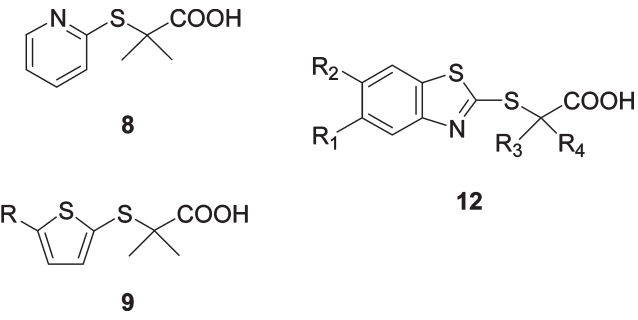

were selected for the determination of their $\mathrm{EC}_{50}$ values. Results are shown in Table 1 . Compounds $\mathbf{8}$, with pyridine, and 9a, with thiophene, were found inactive on PPAR $\alpha$, while the introduction of a chlorine atom on the 5-position of thiophene (9b) resulted in a significant activation of the receptor $\left(\mathrm{EC}_{50}=1.8 \mu \mathrm{M}\right)$. In the series of (2-benzothiazolyl)thioisobutanoic acids $\mathbf{1 2 a}-\mathbf{k}$, structural modifications focused on substitution of the benzothiazolic ring. While unsubstituted derivative 12a proved inactive, the overall effect of the introduction of substituents in the 5 and 6 positions improved PPAR $\alpha$ agonistic activity except for $\mathbf{1 2} \mathbf{e}$ and $\mathbf{1 2} \mathbf{i}$, which were inactive. Of note, among these compounds was 12c, the 5-bromine derivative, which is characterized by an $\mathrm{EC}_{50}$ value of $2.5 \mu \mathrm{M}$ and is thus $10-20$ times more effective than other compounds of the same series. As reported in previous works, chiral aryloxyacid analogues of clofibric acid were found to exhibit antilipidemic and antiplatelet activity. It has been clearly demonstrated that pharmacological and toxic effects are influenced by chirality. ${ }^{17}$ Recent screening tests of other chiral analogues of clofibric acid have indicated that some are potent PPAR $\alpha / \gamma$ agonists. ${ }^{18}$ On the basis of these findings, we focused on introducing a chiral center in the $\alpha$-position of some of the above-described heterocyclic analogues of clofibric acid (rac-12l-u, $\mathrm{R}_{3}=\mathrm{H}$ ) and the new compounds were preliminarily tested in racemic form. The monomethylated derivatives $\mathrm{rac}-\mathbf{1 2} \mathbf{-}-\mathbf{q}$ did not show significant changes of PPAR $\alpha$ activity in comparison with dimethyl 
Scheme $1^{a}$<smiles>[R]c1cc2nc(SCC(=O)OCC)sc2cc1[R]</smiles>

${ }^{a}$ Reagents and conditions: (a) Na, absolute EtOH, reflux, $\mathrm{N}_{2}$; (b) $1 \mathrm{~N} \mathrm{NaOH}$, room temp; (c) $6 \mathrm{~N} \mathrm{HCl}, 60{ }^{\circ} \mathrm{C}$ for enantiomeric compounds.

Table 1. In Vitro Human PPAR $\alpha$ Transactivation of Test and Reference Compounds

\begin{tabular}{|c|c|c|c|c|c|c|}
\hline compd & $\mathrm{R}_{1}$ & $\mathrm{R}_{2}$ & $\mathrm{R}_{3}$ & $\mathrm{R}_{4}$ & $\mathrm{FA}^{a}$ & $\mathrm{EC}_{50}(\mu \mathrm{M})^{b}$ \\
\hline 8 & & & & & $\mathrm{na}^{c}$ & \\
\hline $9 a$ & & & & & $\mathrm{na}^{c}$ & \\
\hline $9 b$ & & & & & $2.8 \pm 0.2$ & $1.8 \pm 0.1$ \\
\hline $12 a$ & $\mathrm{H}$ & $\mathrm{H}$ & $\mathrm{Me}$ & $\mathrm{Me}$ & $\mathrm{na}^{c}$ & \\
\hline $12 \mathrm{~b}$ & $\mathrm{Cl}$ & $\mathrm{H}$ & $\mathrm{Me}$ & $\mathrm{Me}$ & $1.6 \pm 0.1$ & $35.9 \pm 2.7$ \\
\hline $12 \mathrm{c}$ & $\mathrm{Br}$ & $\mathrm{H}$ & $\mathrm{Me}$ & $\mathrm{Me}$ & $4.5 \pm 1.0$ & $2.5 \pm 0.1$ \\
\hline 12d & $\mathrm{CN}$ & $\mathrm{H}$ & $\mathrm{Me}$ & $\mathrm{Me}$ & $1.9 \pm 0.6$ & $46.3 \pm 3.6$ \\
\hline $12 \mathrm{e}$ & $\mathrm{CF}_{3}$ & $\mathrm{H}$ & $\mathrm{Me}$ & $\mathrm{Me}$ & $\mathrm{na}^{c}$ & \\
\hline $12 \mathrm{f}$ & $\mathrm{OMe}$ & $\mathrm{H}$ & $\mathrm{Me}$ & $\mathrm{Me}$ & $2.0 \pm 0.2$ & $45.8 \pm 3.9$ \\
\hline $12 \mathrm{~g}$ & $\mathrm{H}$ & $\mathrm{Cl}$ & $\mathrm{Me}$ & $\mathrm{Me}$ & $1.7 \pm 0.1$ & $38.9 \pm 2.5$ \\
\hline $12 \mathrm{~h}$ & $\mathrm{H}$ & $\mathrm{Br}$ & $\mathrm{Me}$ & $\mathrm{Me}$ & $2.6 \pm 0.4$ & $45.8 \pm 4.0$ \\
\hline $12 \mathrm{i}$ & $\mathrm{H}$ & $\mathrm{CN}$ & $\mathrm{Me}$ & $\mathrm{Me}$ & $\mathrm{na}^{c}$ & \\
\hline $12 \mathrm{j}$ & $\mathrm{H}$ & $\mathrm{CF}_{3}$ & $\mathrm{Me}$ & $\mathrm{Me}$ & $1.7 \pm 0.2$ & $36.1 \pm 2.9$ \\
\hline $12 k$ & $\mathrm{H}$ & OEt & $\mathrm{Me}$ & $\mathrm{Me}$ & $3.3 \pm 0.8$ & $69.3 \pm 5.4$ \\
\hline rac-12I & $\mathrm{Cl}$ & $\mathrm{H}$ & $\mathrm{H}$ & $\mathrm{Me}$ & $3.4 \pm 0.2$ & $62.5 \pm 5.9$ \\
\hline$r a c-\mathbf{1 2 m}$ & $\mathrm{Br}$ & $\mathrm{H}$ & $\mathrm{H}$ & $\mathrm{Me}$ & $3.2 \pm 0.6$ & $9.3 \pm 0.9$ \\
\hline$r a c-12 n$ & $\mathrm{CN}$ & $\mathrm{H}$ & $\mathrm{H}$ & $\mathrm{Me}$ & $\mathrm{na}^{c}$ & \\
\hline$r a c-120$ & $\mathrm{OMe}$ & $\mathrm{H}$ & $\mathrm{H}$ & $\mathrm{Me}$ & $2.9 \pm 0.2$ & $33.3 \pm 4.5$ \\
\hline$r a c-12 \mathbf{p}$ & $\mathrm{H}$ & $\mathrm{Br}$ & $\mathrm{H}$ & $\mathrm{Me}$ & $1.9 \pm 0.9$ & $84.3 \pm 6.4$ \\
\hline$r a c-\mathbf{1 2 q}$ & $\mathrm{H}$ & OEt & $\mathrm{H}$ & $\mathrm{Me}$ & $2.6 \pm 0.2$ & $9.8 \pm 1.3$ \\
\hline$r a c-12 r$ & $\mathrm{Cl}$ & $\mathrm{H}$ & $\mathrm{H}$ & $n$-Pro & $2.7 \pm 0.6$ & $9.3 \pm 0.9$ \\
\hline rac $-12 \mathrm{~s}$ & $\mathrm{H}$ & OEt & $\mathrm{H}$ & $n$-Pro & $4.7 \pm 0.1$ & $14.8 \pm 1.2$ \\
\hline$r a c-12 t$ & $\mathrm{Cl}$ & $\mathrm{H}$ & $\mathrm{H}$ & $n$-Hex & $\mathrm{na}^{c}$ & \\
\hline$r a c-\mathbf{1 2 u}$ & $\mathrm{Cl}$ & $\mathrm{H}$ & $\mathrm{H}$ & $\mathrm{Ph}$ & $1.6 \pm 0.1$ & $14.3 \pm 1.2$ \\
\hline 7 & & & & & $1.6 \pm 0.2$ & $55.0 \pm 3.9$ \\
\hline 1 & & & & & $2.8 \pm 0.5$ & $0.2 \pm 0.02$ \\
\hline
\end{tabular}

${ }^{a}$ FA: fold activation. Compounds were tested at least three separate experiments at $150 \mu \mathrm{M}$. Only 1 was tested at $1 \mu \mathrm{M}$. The results are expressed with \pm SEM. ${ }^{b}$ Compounds were tested in at least three separate experiments in at five concentrations ranging from 1 to 150 $\mu \mathrm{M}$. The results are expressed with \pm SEM. ${ }^{c}$ Not active.

derivatives. Among them, only rac-12m $\left(\mathrm{R}_{1}=\mathrm{Br}\right)$ and $r a c-\mathbf{1 2 q}$ $\left(\mathrm{R}_{2}=\mathrm{OEt}\right)$ exhibited good values of $\mathrm{EC}_{50}(9.3$ and $9.8 \mu \mathrm{M}$, respectively). Further structural modifications were carried out in the $\alpha$-position to the carboxylic function in order to investigate the influence of more hydrophobic and sterically hindered groups on PPAR $\alpha$ agonistic activity. Compounds with a $n$-propylic chain ( $r a c-12 r, s)$ or a phenyl group ( $r a c-12 u)$ demonstrated an increase in agonistic activity over their $\mathrm{R}_{4}$-methyl-substituted analogues (12k and $\mathbf{1 2} \mathrm{l}$ ), while the further elongation of the substituent ( $n$-hexylic chain, rac-12t) caused loss of activity. The transactivation studies reported in Table 1 show that the position, the size, and the electronic effect of $\mathrm{R}_{1}$ and $\mathrm{R}_{2}$ groups on benzothiazolic ring did not seem to correlate with activity. Indeed, there were no remarkable differences when varying the position and dimensions of substituents and when changing electron-withdrawing with electron-donor groups. Also, the introduction of a chiral center in $\alpha$-position to the carboxylic moiety did not improve the transactivation activity except when using $n$-propyl and phenyl groups as substituents.

Considering the high degree of stereoselectivity generally displayed by PPAR ligands, ${ }^{19}$ we were also interested in the biological evaluation of some optically active derivatives.
Table 2. In Vitro Human PPAR $\alpha$ Transactivation of Racemic and Optically Active $\mathbf{1 2 I}$ and $\mathbf{1 2 0}$

\begin{tabular}{llccccc}
\hline compd & $\mathrm{R}_{1}$ & $\mathrm{R}_{2}$ & $\mathrm{R}_{3}$ & $\mathrm{R}_{4}$ & $\mathrm{FA}^{a}$ & $\mathrm{EC}_{50}(\mu \mathrm{M})^{b}$ \\
\hline rac-12l & $\mathrm{Cl}$ & $\mathrm{H}$ & $\mathrm{H}$ & $\mathrm{Me}$ & $3.4 \pm 0.2$ & $62.5 \pm 5.9$ \\
$(R)$-12l & $\mathrm{Cl}$ & $\mathrm{H}$ & $\mathrm{H}$ & $\mathrm{Me}$ & $4.5 \pm 0.8$ & $73.5 \pm 6.8$ \\
$(S)-\mathbf{1 2 l}$ & $\mathrm{Cl}$ & $\mathrm{H}$ & $\mathrm{H}$ & $\mathrm{Me}$ & $2.6 \pm 1.6$ & $55.9 \pm 5.2$ \\
rac-120 & $\mathrm{OMe}$ & $\mathrm{H}$ & $\mathrm{H}$ & $\mathrm{Me}$ & $2.9 \pm 0.2$ & $33.3 \pm 4.5$ \\
$(R)-\mathbf{1 2 0}$ & $\mathrm{OMe}$ & $\mathrm{H}$ & $\mathrm{H}$ & $\mathrm{Me}$ & $2.3 \pm 0.3$ & $57.3 \pm 4.7$ \\
$(S)-\mathbf{1 2 0}$ & $\mathrm{OMe}$ & $\mathrm{H}$ & $\mathrm{H}$ & $\mathrm{Me}$ & $2.9 \pm 0.3$ & $1.9 \pm 0.1$ \\
$\mathbf{7}$ & & & & & $1.6 \pm 0.2$ & $55.0 \pm 3.9$ \\
$\mathbf{1}$ & & & & & $2.8 \pm 0.5$ & $0.2 \pm 0.02$ \\
\hline
\end{tabular}

${ }^{a}$ FA: fold activation. Compounds were tested at least three separate experiments at $150 \mu \mathrm{M}$. Only 1 was tested at $1 \mu \mathrm{M}$. The results are expressed with \pm SEM. ${ }^{b}$ Compounds were tested in at least three separate experiments in at five concentrations ranging from 1 to 150 $\mu \mathrm{M}$. The results are expressed with \pm SEM.

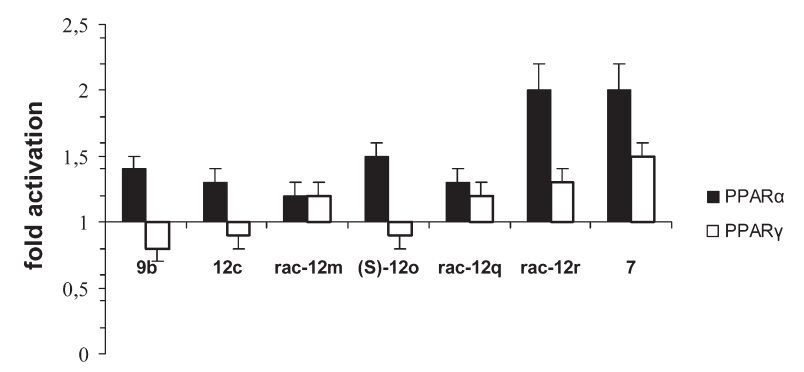

Figure 3. Selectivity PPAR $\alpha / \gamma$.

Enantiomerically pure $(R)$ - and $(S)$-12l and $(R)$ - and $(S)$-12o acids were synthesized and tested. Data in Table 2 confirm the greater activity of $(S)$-isomers, in agreement with previous studies. ${ }^{19}$ In particular, a clear stereopreference was found with $(S)-\mathbf{1 2 0}$, which exhibited more potent transactivation activity $\left(\mathrm{EC}_{50}=1.9 \mu \mathrm{M}\right)$ than the antipodal $(R)$-isomer $\left(\mathrm{EC}_{50}=57.3 \mu \mathrm{M}\right)$.

The fibrate analogues described in this work have, like the most selective PPAR $\alpha$ activators, an aromatic system connected to an acidic headgroup. Although they are less potent than the compounds with a long hydrophobic tail linked to the aromatic scaffold, better values of $\mathrm{EC}_{50}$ than the classical fibrates were observed.

All compounds showing good activation of PPAR $\alpha$ receptor $\left(\mathrm{EC}_{50}<10 \mu \mathrm{M}\right)$ were preliminarily tested on PPAR $\gamma$ in order to explore a possible selective activation of these receptors. We performed the transactivation assay on both PPAR $\alpha$ and PPAR $\gamma$ isoforms, testing each compound at a concentration of PPAR $\alpha \mathrm{EC}_{50}$. By comparing fold activation values, we observed the preferential activation of $\alpha$-isoform for compounds $9 \mathbf{b}, \mathbf{1 2 c}$, and $(S)$-12o (Figure 3 ). This evaluation is only a qualitative overview; however, is noteworthy that best selectivity profiles PPAR $\alpha / \gamma$ were obtained for compounds more active on PPAR $\alpha\left(\mathrm{EC}_{50}\right.$ values within $\left.3 \mu \mathrm{M}\right)$.

The gene carnitine palmitoyl transferase 1A (CPT1A) has been previously shown to be induced in human hepatocytes and hepatoma cells in response to $\operatorname{PPAR} \alpha$ agonists; the investigation of CPT1A expression is a well established in 


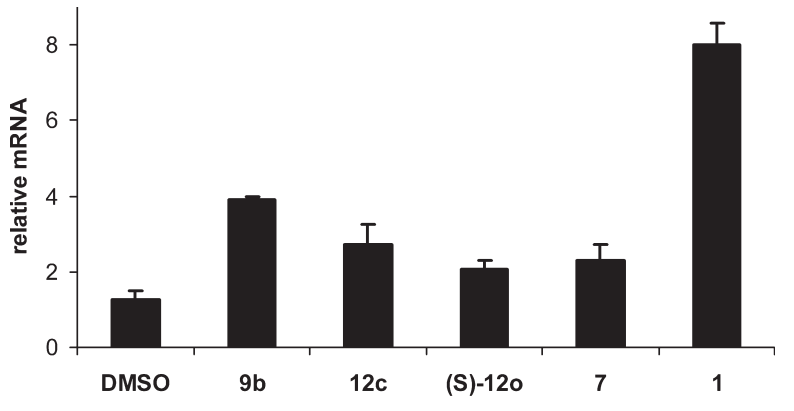

Figure 4. CPT1A expression in HepG2 following treatment. Cells were treated with vehicle (DMSO), 1, 7, 9b, 12c, and $(S)-\mathbf{1 2 0}$ at $150 \mu \mathrm{M}$ for $48 \mathrm{~h}$. RTqPCR was performed to measure CPT1A mRNA levels. Values shown represent the mean \pm SEM of four independent determinations performed in duplicate. Cyclophilin was used as reference gene, and values were normalized to data obtained from vehicle treated cells.

vitro model to study PPAR $\alpha$ activation. ${ }^{20}$ On the basis of the transactivation assay results, we selected $\mathbf{9 b}, \mathbf{1 2 c}$, and $(S)-\mathbf{1 2 0}$ for the in vitro analysis of CPT1A expression in human hepatocellular liver carcinoma cell line (HepG2) by using real-time quantitative polymerase chain reaction (RTqPCR). As shown in Figure 4, a pronounced increase of gene expression of about 8-fold was detected when cells were treated for $48 \mathrm{~h}$ with reference compound 1, while CPT1A mRNA levels were doubled with control 7, according to the fibrate activity. ${ }^{20}$ Treatment with $9 \mathbf{b}$ increased the expression of gene by 2-fold, while compounds $\mathbf{1 2 c}$ and $(S)$-12o displayed mRNA levels similar to control 7.

\section{Conclusions}

A new series of clofibric acid analogues was synthesized and in vitro evaluated for human $\operatorname{PPAR} \alpha$ activity by transactivation assay. Overall, the potencies of some newly designed agonists were slightly higher than those of typical fibrates, such as clofibrate. The best findings were obtained with compounds $\mathbf{9 b}, \mathbf{1 2 c}$, and $(S)-\mathbf{1 2 0}$, showing $\mathrm{EC}_{50}$ values within $3 \mu \mathrm{M}$. Selectivity experiments on the PPAR $\gamma$ isoform also demonstrated their preferential activation of $\alpha$-isoform. Also, the effects of gene induction were investigated by the analysis of CPT1A expression in the HepG2 cell line: compound $9 \mathbf{b}$ was remarkably twice as effective as control 7 , making it a prime candidate as a new lead compound for the design of more potent and selective PPAR $\alpha$ agonist analogues of fibrates.

\section{Experimental Section}

Chemistry. General. Melting points were determined on a Buchi B-540 apparatus and are uncorrected. Infrared spectra (IR) were recorded on a FT-IR 1600 Perkin-Elmer spectrometer. NMR spectra were run at $300 \mathrm{MHz}$ on a Varian instrument; chemical shifts $(\delta)$ are reported in ppm. Microanalyses were carried out with an Eurovector Euro EA 3000 model analyzer, and the analytical results were within $0.4 \%$ of the theoretical values. Commercial reagents were used as received from Aldrich or Fluka. The optically active acids $(R)$ - and $(S)$ 12l and 12o had enantiomeric excesses (ee) greater than $98 \%$ determined by using an HPLC device (Waters Association, Milford, MA) equipped with a Chiralpack AD or AI chiral column $(25 \mathrm{~cm} \times 4.6 \mathrm{~mm})$ (Daicel Chemical Industries Ltd., Japan) connected to an UV detector (254 nm): mobile phase, $n$-Hex $/ \mathrm{EtOH}=95 / 5+0.05 \%$ TFA; flow rate, $1.0 \mathrm{~mL} / \mathrm{min}$.

Compounds 8, 9a,b, 11a,b, and 12a,b have been previously described. ${ }^{14,15}$
General Procedure for the Preparation of Esters 11c-k and rac-11l-u. The heterocyclic thiol $(3.0 \mathrm{mmol})$ and ethyl 2-bromoalkanoate $(3.0 \mathrm{mmol})$, both dissolved in absolute $\mathrm{EtOH}$ $(10 \mathrm{~mL})$, were added to a solution of sodium $(69.0 \mathrm{mg}, 3.0 \mathrm{mmol})$ in absolute EtOH $(10 \mathrm{~mL})$ under nitrogen atmosphere. After the mixture was stirred for $2-5 \mathrm{~h}$ at reflux, the solvent was removed under reduced pressure. The residue was poured into water $(20 \mathrm{~mL})$ and extracted with diethyl ether $(3 \times 20 \mathrm{~mL})$. The organic layer was dried over $\mathrm{Na}_{2} \mathrm{SO}_{4}$ and concentrated under reduced pressure. The residue was purified by column chromatography on silica gel (eluent cyclohexane/ethyl acetate, 95:5).

Ethyl 2-[(5-Bromo-1,3-benzothiazol-2-yl)thio]-2-methylpropanoate (11c). Orange-yellow oil, 47\% yield. IR (KBr) 1728 $\mathrm{cm}^{-1} ;{ }^{1} \mathrm{H}$ NMR $\left(\mathrm{CDCl}_{3}\right) \delta 1.21\left(\mathrm{t}, 3 \mathrm{H}, J=7.2 \mathrm{~Hz}, \mathrm{CH}_{3} \mathrm{CH}_{2}\right)$, $1.75\left(\mathrm{~s}, 6 \mathrm{H}, \mathrm{C}\left(\mathrm{CH}_{3}\right)_{2}\right), 4.20\left(\mathrm{q}, 2 \mathrm{H}, \mathrm{J}=7.2 \mathrm{~Hz}, \mathrm{CH}_{2} \mathrm{CH}_{3}\right)$, $7.41-7.45(\mathrm{dd}, 1 \mathrm{H}, J=8.7 \mathrm{~Hz}, J=2.1 \mathrm{~Hz}, \mathrm{CH} \mathrm{Ar}), 7.62(\mathrm{~d}, 1 \mathrm{H}$, $J=8.7 \mathrm{~Hz}, \mathrm{CH} \mathrm{Ar}), 8.04(\mathrm{~d}, 1 \mathrm{H}, J=2.1 \mathrm{~Hz}, \mathrm{CH} \mathrm{Ar}) ;{ }^{13} \mathrm{C} \mathrm{NMR}$

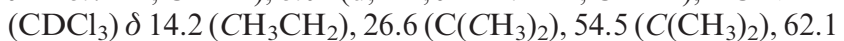
$\left(\mathrm{CH}_{2} \mathrm{CH}_{3}\right), 119.9(\mathrm{C} \mathrm{Ar}), 122.2,125.3$, and $128.1(\mathrm{CH} \mathrm{Ar}), 135.0$ and $154.6(C \mathrm{Ar}), 164.9(=C-\mathrm{S}), 173.3 \quad(C=\mathrm{O})$. Anal. $\left(\mathrm{C}_{12} \mathrm{H}_{14} \mathrm{BrNO}_{2} \mathrm{~S}_{2}\right) \mathrm{C}, \mathrm{H}, \mathrm{N}$.

Ethyl 2-[(5-Cyano-1,3-benzothiazol-2-yl)thio]-2-methylpropanoate (11d). Yellowish oil, 72\% yield. IR (KBr) 2229, 1733 $\mathrm{cm}^{-1} ;{ }^{1} \mathrm{H} \mathrm{NMR}\left(\mathrm{CDCl}_{3}\right) \delta 1.22\left(\mathrm{t}, 3 \mathrm{H}, J=7.2 \mathrm{~Hz}, \mathrm{CH}_{3} \mathrm{CH}_{2}\right)$, $1.78\left(\mathrm{~s}, 6 \mathrm{H}, \mathrm{C}\left(\mathrm{CH}_{3}\right)_{2}\right), 4.21\left(\mathrm{q}, 2 \mathrm{H}, \mathrm{J}=7.2 \mathrm{~Hz}, \mathrm{CH}_{2} \mathrm{CH}_{3}\right)$, $7.53-7.56(\mathrm{dd}, 1 \mathrm{H}, J=8.1 \mathrm{~Hz}, J=1.5 \mathrm{~Hz}, \mathrm{CH} \mathrm{Ar}), 7.86(\mathrm{~d}, 1 \mathrm{H}$, $J=8.1 \mathrm{~Hz}, \mathrm{CH} \mathrm{Ar}), 8.13(\mathrm{~d}, 1 \mathrm{H}, J=1.5 \mathrm{~Hz}, \mathrm{CH} \mathrm{Ar}) ;{ }^{13} \mathrm{C} \mathrm{NMR}$

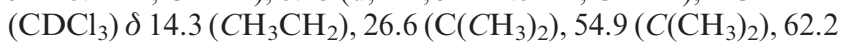
$\left(\mathrm{CH}_{2} \mathrm{CH}_{3}\right), 110.0(\mathrm{C} \mathrm{Ar}), 118.93(\mathrm{CN}), 122.2,126.0$, and 127.3 $(C \mathrm{H} \mathrm{Ar}), 140.9$ and $153.0(C \mathrm{Ar}), 166.9(=C-\mathrm{S}), 173.1(C=\mathrm{O})$. Anal. $\left(\mathrm{C}_{14} \mathrm{H}_{14} \mathrm{~N}_{2} \mathrm{O}_{2} \mathrm{~S}_{2}\right) \mathrm{C}, \mathrm{H}, \mathrm{N}$.

Ethyl 2-[(5-Trifluoromethyl-1,3-benzothiazol-2-yl)thio]-2-methylpropanoate (11e). Yellowish oil, $62 \%$ yield. IR (KBr) $1735 \mathrm{~cm}^{-1}$; ${ }^{1} \mathrm{H} \mathrm{NMR}\left(\mathrm{CDCl}_{3}\right) \delta 1.21\left(\mathrm{t}, 3 \mathrm{H}, J=7.2 \mathrm{~Hz}, \mathrm{CH}_{3} \mathrm{CH}_{2}\right), 1.78(\mathrm{~s}, 6 \mathrm{H}$, $\left.\mathrm{C}\left(\mathrm{CH}_{3}\right)_{2}\right), 4.21\left(\mathrm{q}, 2 \mathrm{H}, J=7.2 \mathrm{~Hz}, \mathrm{CH}_{2} \mathrm{CH}_{3}\right), 7.56(\mathrm{dd}, 1 \mathrm{H}, J=$ $8.4 \mathrm{~Hz}, J=1.8 \mathrm{~Hz}, \mathrm{CH} \mathrm{Ar}), 7.87(\mathrm{~d}, 1 \mathrm{H}, J=8.4 \mathrm{~Hz}, \mathrm{CH} \mathrm{Ar}), 8.13$ $(\mathrm{d}, 1 \mathrm{H}, J=1.8 \mathrm{~Hz}, \mathrm{CH} \mathrm{Ar}) ;{ }^{13} \mathrm{C} \mathrm{NMR}\left(\mathrm{CDCl}_{3}\right) \delta 14.2\left(\mathrm{CH}_{3} \mathrm{CH}_{2}\right)$,

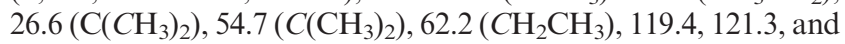
$121.7(\mathrm{CH} \mathrm{Ar}), 128.8\left(\mathrm{CF}_{3}\right), 129.2,139.1,153.1$, and $165.8(C \mathrm{Ar})$, $173.2(C=\mathrm{O})$. Anal. $\left(\mathrm{C}_{14} \mathrm{H}_{14} \mathrm{~F}_{3} \mathrm{NO}_{2} \mathrm{~S}_{2}\right) \mathrm{C}, \mathrm{H}, \mathrm{N}$.

Ethyl 2-[(5-Methoxy-1,3-benzothiazol-2-yl)thio]-2-methylpropanoate (11f). Yellowish oil, $42 \%$ yield. IR $(\mathrm{KBr}) 1729 \mathrm{~cm}^{-1} ;{ }^{1} \mathrm{H}$ $\operatorname{NMR}\left(\mathrm{CDCl}_{3}\right) \delta 1.20\left(\mathrm{t}, 3 \mathrm{H}, J=7.2 \mathrm{~Hz}, \mathrm{CH}_{3} \mathrm{CH}_{2}\right), 1.74(\mathrm{~s}, 6 \mathrm{H}$, $\left.\mathrm{C}\left(\mathrm{CH}_{3}\right)_{2}\right), 3.87\left(\mathrm{~s}, 3 \mathrm{H}, \mathrm{OCH}_{3}\right), 4.19(\mathrm{q}, 2 \mathrm{H}, J=7.2 \mathrm{~Hz}$, $\left.\mathrm{CH}_{2} \mathrm{CH}_{3}\right), 6.97-7.01(\mathrm{dd}, 1 \mathrm{H}, J=8.7 \mathrm{~Hz}, J=2.7 \mathrm{~Hz}, \mathrm{CH}$ Ar), $7.42(\mathrm{~d}, 1 \mathrm{H}, J=2.7 \mathrm{~Hz}, \mathrm{CH} \mathrm{Ar}), 7.62(\mathrm{~d}, 1 \mathrm{H}, J=8.7 \mathrm{~Hz}$, $\mathrm{CH} \mathrm{Ar}) ;{ }^{13} \mathrm{C} \mathrm{NMR}\left(\mathrm{CDCl}_{3}\right) \delta 14.2\left(\mathrm{CH}_{3} \mathrm{CH}_{2}\right), 26.6\left(\mathrm{C}\left(\mathrm{CH}_{3}\right)_{2}\right)$,

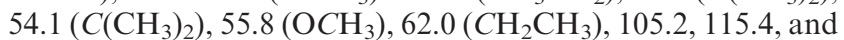
126.4 (CH Ar), 128.5, 154.8, and 159.1 ( $C \mathrm{Ar}), 163.0(=C-\mathrm{S})$, $173.5(C=\mathrm{O})$. Anal. $\left(\mathrm{C}_{14} \mathrm{H}_{17} \mathrm{NO}_{3} \mathrm{~S}_{2}\right) \mathrm{C}, \mathrm{H}, \mathrm{N}$.

Ethyl 2-[(6-Chloro-1,3-benzothiazol-2-yl)thio]-2-methylpropanoate (11g). Yellowish oil, 46\% yield. IR (KBr) $1729 \mathrm{~cm}^{-1}$; ${ }^{1} \mathrm{H} \mathrm{NMR}\left(\mathrm{CDCl}_{3}\right) \delta 1.19\left(\mathrm{t}, 3 \mathrm{H}, J=7.2 \mathrm{~Hz}, \mathrm{CH}_{3} \mathrm{CH}_{2}\right), 1.74(\mathrm{~s}$, $\left.6 \mathrm{H}, \mathrm{C}\left(\mathrm{CH}_{3}\right)_{2}\right), 4.19\left(\mathrm{q}, 2 \mathrm{H}, J=7.2 \mathrm{~Hz}, \mathrm{CH}_{2} \mathrm{CH}_{3}\right), 7.38(\mathrm{dd}, 1 \mathrm{H}$, $J=9.0 \mathrm{~Hz}, J=1.8 \mathrm{~Hz}, \mathrm{CH} \mathrm{Ar}), 7.75(\mathrm{~d}, 1 \mathrm{H}, J=1.8 \mathrm{~Hz}, \mathrm{CH}$ Ar), $7.80(\mathrm{~d}, 1 \mathrm{H}, J=9.0 \mathrm{~Hz}, \mathrm{CH} \mathrm{Ar}) ;{ }^{13} \mathrm{C} \mathrm{NMR}\left(\mathrm{CDCl}_{3}\right) \delta 14.2$ $\left(\mathrm{CH}_{3} \mathrm{CH}_{2}\right), 26.6\left(\mathrm{C}\left(\mathrm{CH}_{3}\right)_{2}\right), 54.4\left(\mathrm{C}\left(\mathrm{CH}_{3}\right)_{2}\right), 62.1\left(\mathrm{CH}_{2} \mathrm{CH}_{3}\right)$, 120.8, 123.2, and 127.1 (CH Ar), 131.1, 137.6, 152.0, and 163.2 (C Ar), $173.3(C=\mathrm{O})$. Anal. $\left(\mathrm{C}_{13} \mathrm{H}_{14} \mathrm{ClNO}_{2} \mathrm{~S}_{2}\right) \mathrm{C}, \mathrm{H}, \mathrm{N}$.

Ethyl 2-[(6-Bromo-1,3-benzothiazol-2-yl)thio]-2-methylpropanoate $(11 \mathrm{~h})$. Yellowish oil, $63 \%$ yield. IR (KBr) $1741 \mathrm{~cm}^{-1}$; ${ }^{1} \mathrm{H} \mathrm{NMR}\left(\mathrm{CDCl}_{3}\right) \delta 1.19\left(\mathrm{t}, 3 \mathrm{H}, J=7.2 \mathrm{~Hz}, \mathrm{CH}_{3} \mathrm{CH}_{2}\right), 1.74(\mathrm{~s}$, $\left.6 \mathrm{H}, \mathrm{C}\left(\mathrm{CH}_{3}\right)_{2}\right), 4.19\left(\mathrm{q}, 2 \mathrm{H}, J=7.2 \mathrm{~Hz}, \mathrm{CH}_{2} \mathrm{CH}_{3}\right), 7.52(\mathrm{dd}, 1 \mathrm{H}$, $J=8.7 \mathrm{~Hz}, J=2.1 \mathrm{~Hz}, \mathrm{CH} \mathrm{Ar}), 7.74(\mathrm{~d}, 1 \mathrm{H}, J=8.7 \mathrm{~Hz}, \mathrm{CH}$ $\mathrm{Ar}), 7.90(\mathrm{~d}, 1 \mathrm{H}, J=2.1 \mathrm{~Hz}, \mathrm{CH} \mathrm{Ar}) ;{ }^{13} \mathrm{C} \mathrm{NMR}\left(\mathrm{CDCl}_{3}\right) \delta 14.2$ $\left(\mathrm{CH}_{3} \mathrm{CH}_{2}\right), 26.6\left(\mathrm{C}\left(\mathrm{CH}_{3}\right)_{2}\right), 54.4\left(\mathrm{C}\left(\mathrm{CH}_{3}\right)_{2}\right), 62.1\left(\mathrm{CH}_{2} \mathrm{CH}_{3}\right)$, 118.7 (C Ar), 123.6, 123.7, and 129.8 (CH Ar), 138.0, 152.3, and $163.4(C \mathrm{Ar}), 173.3(C=\mathrm{O})$. Anal. $\left(\mathrm{C}_{13} \mathrm{H}_{14} \mathrm{BrNO}_{2} \mathrm{~S}_{2}\right) \mathrm{C}, \mathrm{H}, \mathrm{N}$.

Ethyl 2-[(6-Cyano-1,3-benzothiazol-2-yl)thio]-2-methylpropanoate (11i). White solid, $47 \%$ yield. IR (KBr) 2225, $1720 \mathrm{~cm}^{-1}$; mp 
88-89 ${ }^{\circ} \mathrm{C} ;{ }^{1} \mathrm{H}$ NMR $\left(\mathrm{CDCl}_{3}\right) \delta 1.19(\mathrm{t}, 3 \mathrm{H}, J=7.2 \mathrm{~Hz}$, $\left.\mathrm{CH}_{3} \mathrm{CH}_{2}\right), 1.79\left(\mathrm{~s}, 6 \mathrm{H}, \mathrm{C}\left(\mathrm{CH}_{3}\right)_{2}\right), 4.20(\mathrm{q}, 2 \mathrm{H}, J=7.2 \mathrm{~Hz}$, $\left.\mathrm{CH}_{2} \mathrm{CH}_{3}\right), 7.66(\mathrm{dd}, 1 \mathrm{H}, J=8.4 \mathrm{~Hz}, J=1.5 \mathrm{~Hz}, \mathrm{CH} \mathrm{Ar}), 7.90$ $(\mathrm{d}, 1 \mathrm{H}, J=8.4 \mathrm{~Hz}, \mathrm{CH} \mathrm{Ar}), 8.08(\mathrm{~d}, 1 \mathrm{H}, J=1.5 \mathrm{~Hz}, \mathrm{CH} \mathrm{Ar}) ;{ }^{13} \mathrm{C}$ NMR $\left(\mathrm{CDCl}_{3}\right) \quad \delta \quad 14.2\left(\mathrm{CH}_{3} \mathrm{CH}_{2}\right), 26.6 \quad\left(\mathrm{C}\left(\mathrm{CH}_{3}\right)_{2}\right), \quad 54.9$ $\left(C\left(\mathrm{CH}_{3}\right)_{2}\right), 62.2\left(\mathrm{CH}_{2} \mathrm{CH}_{3}\right), 108.1(\mathrm{C} \mathrm{Ar}), 118.9(\mathrm{CN}), 122.7$, 125.7, and 129.6 ( $\mathrm{CH} \mathrm{Ar}), 136.3,155.7$, and 169.0 (C Ar), 173.1 $(C=\mathrm{O})$. Anal. $\left(\mathrm{C}_{14} \mathrm{H}_{14} \mathrm{~N}_{2} \mathrm{O}_{2} \mathrm{~S}_{2}\right) \mathrm{C}, \mathrm{H}, \mathrm{N}$.

Ethyl 2-[(6-Trifluoromethyl-1,3-benzothiazol-2-yl)thio]-2-methylpropanoate (11j). Yellowish oil, 71\% yield. IR (KBr) $1734 \mathrm{~cm}^{-1} ;{ }^{1} \mathrm{H}$ NMR $\left(\mathrm{CDCl}_{3}\right) \delta 1.20\left(\mathrm{t}, 3 \mathrm{H}, J=7.2 \mathrm{~Hz}, \mathrm{CH}_{3} \mathrm{CH}_{2}\right), 1.78(\mathrm{~s}, 6 \mathrm{H}$, $\left.\mathrm{C}\left(\mathrm{CH}_{3}\right)_{2}\right), 4.20\left(\mathrm{q}, 2 \mathrm{H}, J=7.2 \mathrm{~Hz}, \mathrm{CH}_{2} \mathrm{CH}_{3}\right), 7.65(\mathrm{dd}, 1 \mathrm{H}, J=$ $8.4 \mathrm{~Hz}, J=1.8 \mathrm{~Hz}, \mathrm{CH} \mathrm{Ar}), 7.94(\mathrm{~d}, 1 \mathrm{H}, J=8.4 \mathrm{~Hz}, \mathrm{CH} \mathrm{Ar}), 8.06$ $(\mathrm{d}, 1 \mathrm{H}, J=1.8 \mathrm{~Hz}, \mathrm{CH} \mathrm{Ar}) ;{ }^{13} \mathrm{C} \mathrm{NMR}\left(\mathrm{CDCl}_{3}\right) \delta 14.2\left(\mathrm{CH}_{3} \mathrm{CH}_{2}\right)$,

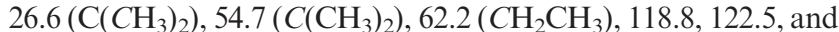
$123.3(C \mathrm{H} \mathrm{Ar}), 126.1\left(C \mathrm{~F}_{3}\right), 127.2,136.1,155.8$, and $167.0(C \mathrm{Ar})$, $173.2(C=\mathrm{O})$. Anal. $\left(\mathrm{C}_{14} \mathrm{H}_{14} \mathrm{~F}_{3} \mathrm{NO}_{2} \mathrm{~S}_{2}\right) \mathrm{C}, \mathrm{H}, \mathrm{N}$.

Ethyl 2-[(6-Ethoxy-1,3-benzothiazol-2-yl)thio]-2-methylpropanoate (11k). Yellowish solid, $48 \%$ yield. IR (KBr) $1727 \mathrm{~cm}^{-1}$; mp 77-78 ${ }^{\circ} \mathrm{C} ;{ }^{1} \mathrm{H} \mathrm{NMR}\left(\mathrm{CDCl}_{3}\right) \delta 1.20(\mathrm{t}, 3 \mathrm{H}, J=7.2 \mathrm{~Hz}$, $\mathrm{CH}_{3} \mathrm{CH}_{2} \mathrm{O}$ ), 1.43 (t, 3H, $\left.J=7.2 \mathrm{~Hz}, \mathrm{CH}_{3} \mathrm{CH}_{2} \mathrm{OAr}\right), 1.70$ (s, $6 \mathrm{H}$, $\left.\mathrm{C}\left(\mathrm{CH}_{3}\right)_{2}\right), 4.06\left(\mathrm{q}, 2 \mathrm{H}, J=7.2 \mathrm{~Hz}, \mathrm{OCH}_{2} \mathrm{CH}_{3}\right), 4.18(\mathrm{q}, 2 \mathrm{H}, J=$ $\left.7.2 \mathrm{~Hz}, \mathrm{ArOCH} \mathrm{CH}_{3}\right), 7.03(\mathrm{dd}, 1 \mathrm{H}, J=8.7 \mathrm{~Hz}, J=2.4 \mathrm{~Hz}, \mathrm{CH}$ $\mathrm{Ar}), 7.22(\mathrm{~d}, 1 \mathrm{H}, J=2.4 \mathrm{~Hz}, \mathrm{CH} \mathrm{Ar}), 7.83(\mathrm{~d}, 1 \mathrm{H}, J=8.7 \mathrm{~Hz}, \mathrm{CH}$ $\mathrm{Ar}) ;{ }^{13} \mathrm{C} \mathrm{NMR}\left(\mathrm{CDCl}_{3}\right) \delta 14.2\left(\mathrm{CH}_{3} \mathrm{CH}_{2} \mathrm{O}\right), 15.0\left(\mathrm{CH}_{3} \mathrm{CH}_{2} \mathrm{OAr}\right)$, $26.5\left(\mathrm{C}\left(\mathrm{CH}_{3}\right)_{2}\right), 54.1\left(\mathrm{C}\left(\mathrm{CH}_{3}\right)_{2}\right), 62.0\left(\mathrm{OCH}_{2} \mathrm{CH}_{3}\right), 64.3$ (ArO$\left.\mathrm{CH}_{2} \mathrm{CH}_{3}\right), 104.3,116.2$, and $123.6(\mathrm{CH} \mathrm{Ar}), 138.6,148.1,157.3$, and $158.0(C \mathrm{Ar}), 173.5(C=\mathrm{O})$. Anal. $\left(\mathrm{C}_{15} \mathrm{H}_{19} \mathrm{NO}_{3} \mathrm{~S}_{2}\right) \mathrm{C}, \mathrm{H}, \mathrm{N}$.

Ethyl 2-[(5-Chloro-1,3-benzothiazol-2-yl)thio]propanoate [( rac $)$ 111]. Yellowish oil, $76 \%$ yield. IR (KBr) $1735 \mathrm{~cm}^{-1} ;{ }^{1} \mathrm{H}$ NMR $\left(\mathrm{CDCl}_{3}\right) \delta 1.27\left(\mathrm{t}, 3 \mathrm{H}, J=7.2 \mathrm{~Hz}, \mathrm{CH}_{3} \mathrm{CH}_{2}\right), 1.72(\mathrm{~d}, 3 \mathrm{H}, J=$ $\left.7.5 \mathrm{~Hz}, \mathrm{CH}_{3} \mathrm{CH}\right), 4.20\left(\mathrm{q}, 2 \mathrm{H}, J=7.2 \mathrm{~Hz}, \mathrm{CH}_{2} \mathrm{CH}_{3}\right), 4.69$ (q, $1 \mathrm{H}$, $\left.J=7.5 \mathrm{~Hz}, \mathrm{CH}_{3} \mathrm{CH}\right), 7.27-7.30(\mathrm{dd}, 1 \mathrm{H}, J=8.4 \mathrm{~Hz}, J=1.8 \mathrm{~Hz}$, $\mathrm{CH} \mathrm{Ar}), 7.67(\mathrm{~d}, 1 \mathrm{H}, J=8.4 \mathrm{~Hz}, \mathrm{CH} \mathrm{Ar}), 7.84(\mathrm{~d}, 1 \mathrm{H}, J=1.8 \mathrm{~Hz}$, $\mathrm{CH} \mathrm{Ar}) ;{ }^{13} \mathrm{C}$ NMR $\left(\mathrm{CDCl}_{3}\right) \delta 14.3\left(\mathrm{CH}_{3} \mathrm{CH}_{2}\right), 18.1\left(\mathrm{CH}_{3} \mathrm{CH}\right)$, $45.4\left(\mathrm{CH}_{3} \mathrm{CH}\right), 62.1\left(\mathrm{CH}_{2} \mathrm{CH}_{3}\right), 121.8,121.9$, and $125.1(\mathrm{CH} \mathrm{Ar})$, 132.4 $(C \mathrm{Cl}), 133.9$ and $154.0(C \mathrm{Ar}), 166.9(=C-\mathrm{S}), 171.7(C=\mathrm{O})$. Anal. $\left(\mathrm{C}_{12} \mathrm{H}_{12} \mathrm{ClNO}_{2} \mathrm{~S}_{2}\right) \mathrm{C}, \mathrm{H}, \mathrm{N}$.

Ethyl 2-[(5-Bromo-1,3-benzothiazol-2-yl)thio]propanoate [( rac $)$ $11 \mathrm{~m}$. Yellowish oil, $67 \%$ yield. IR (KBr) $1732 \mathrm{~cm}^{-1}$; ${ }^{1} \mathrm{H}$ NMR $\left(\mathrm{CDCl}_{3}\right) \delta 1.27\left(\mathrm{t}, 3 \mathrm{H}, J=6.9 \mathrm{~Hz}, \mathrm{CH}_{3} \mathrm{CH}_{2}\right), 1.71(\mathrm{~d}, 3 \mathrm{H}, J=$ $\left.7.2 \mathrm{~Hz}, \mathrm{CH}_{3} \mathrm{CH}\right), 4.22\left(\mathrm{q}, 2 \mathrm{H}, J=6.9 \mathrm{~Hz}, \mathrm{CH}_{2} \mathrm{CH}_{3}\right), 4.68(\mathrm{q}, 1 \mathrm{H}$, $\left.J=7.2 \mathrm{~Hz}, \mathrm{CH}_{3} \mathrm{CH}\right), 7.39-7.44(\mathrm{dd}, 1 \mathrm{H}, J=8.7 \mathrm{~Hz}, J=1.8 \mathrm{~Hz}$, $\mathrm{CH} \mathrm{Ar}), 7.60(\mathrm{~d}, 1 \mathrm{H}, J=8.7 \mathrm{~Hz}, \mathrm{CH} \mathrm{Ar}), 8.00(\mathrm{~d}, 1 \mathrm{H}, J=1.8 \mathrm{~Hz}$, $\mathrm{CH} \mathrm{Ar}) ;{ }^{13} \mathrm{C} \mathrm{NMR}\left(\mathrm{CDCl}_{3}\right) \delta 14.3\left(\mathrm{CH}_{3} \mathrm{CH}_{2}\right), 18.1\left(\mathrm{CH}_{3} \mathrm{CH}\right)$, $45.4\left(\mathrm{CH}_{3} \mathrm{CH}\right), 62.1\left(\mathrm{CH}_{2} \mathrm{CH}_{3}\right), 119.9(\mathrm{CBr}), 122.2,124.8$, and 127.7 ( $C \mathrm{H} \mathrm{Ar}), 134.5$ and $145.1(C \mathrm{Ar}), 154.3(=C-\mathrm{S}), 171.6$ $(C=\mathrm{O})$. Anal. $\left(\mathrm{C}_{12} \mathrm{H}_{12} \mathrm{BrNO}_{2} \mathrm{~S}_{2}\right) \mathrm{C}, \mathrm{H}, \mathrm{N}$.

Ethyl 2-[(5-Cyano-1,3-benzothiazol-2-yl)thio]propanoate [(rac)11n]. Yellowish oil, $78 \%$ yield. IR $(\mathrm{KBr}) 2234,1732 \mathrm{~cm}^{-1} ;{ }^{1} \mathrm{H}$ $\operatorname{NMR}\left(\mathrm{CDCl}_{3}\right) \delta 1.28\left(\mathrm{t}, 3 \mathrm{H}, J=6.9 \mathrm{~Hz}, \mathrm{CH}_{3} \mathrm{CH}_{2}\right), 1.72(\mathrm{~d}, 3 \mathrm{H}$, $\left.J=7.2 \mathrm{~Hz}, \mathrm{CH}_{3} \mathrm{CH}\right), 4.25\left(\mathrm{q}, 2 \mathrm{H}, J=6.9 \mathrm{~Hz}, \mathrm{CH}_{2} \mathrm{CH}_{3}\right), 4.73$ (q, $\left.1 \mathrm{H}, J=7.2 \mathrm{~Hz}, \mathrm{CH}_{3} \mathrm{CH}\right), 7.52-7.56(\mathrm{dd}, 1 \mathrm{H}, J=8.4 \mathrm{~Hz}, J=$ $1.8 \mathrm{~Hz}, \mathrm{CH} \mathrm{Ar}), 7.85(\mathrm{~d}, 1 \mathrm{H}, J=8.4 \mathrm{~Hz}, \mathrm{CH} \mathrm{Ar}), 8,11(\mathrm{~d}, 1 \mathrm{H}, J=$ $1.8 \mathrm{~Hz}, \mathrm{CH} \mathrm{Ar}) ;{ }^{13} \mathrm{C} \mathrm{NMR}\left(\mathrm{CDCl}_{3}\right) \delta 14.3\left(\mathrm{CH}_{3} \mathrm{CH}_{2}\right), 18.1$ $\left(\mathrm{CH}_{3} \mathrm{CH}\right), 45.5\left(\mathrm{CH}_{3} \mathrm{CH}\right), 62.2\left(\mathrm{CH}_{2} \mathrm{CH}_{3}\right), 110.0(\mathrm{CCN}), 118.9$ $(C \mathrm{~N}), 122.3,125.6$, and 127.1 ( $C \mathrm{H} \mathrm{Ar}), 140.7$ and 152.8 ( $C \mathrm{Ar}$ ), $168.3(=C-\mathrm{S}), 171.4(C=\mathrm{O})$. Anal. $\left(\mathrm{C}_{13} \mathrm{H}_{12} \mathrm{~N}_{2} \mathrm{O}_{2} \mathrm{~S}_{2}\right) \mathrm{C}, \mathrm{H}, \mathrm{N}$.

Ethyl 2-[(5-Methoxy-1,3-benzothiazol-2-yl)thio]propanoate [( rac $)$ 110]. White oil, $60 \%$ yield. IR ( $\mathrm{KBr}) 1732 \mathrm{~cm}^{-1}$; ${ }^{1} \mathrm{H}$ NMR $\left(\mathrm{CDCl}_{3}\right)$ $\delta 1.25\left(\mathrm{t}, 3 \mathrm{H}, J=6.9 \mathrm{~Hz}, \mathrm{CH}_{3} \mathrm{CH}_{2}\right), 1.70(\mathrm{~d}, 3 \mathrm{H}, J=7.2 \mathrm{~Hz}$, $\left.\mathrm{CH}_{3} \mathrm{CH}\right), 3.86\left(\mathrm{~s}, 3 \mathrm{H}, \mathrm{OCH}_{3}\right), 4.21\left(\mathrm{q}, 2 \mathrm{H}, J=6.9 \mathrm{~Hz}, \mathrm{CH}_{2} \mathrm{CH}_{3}\right)$, $4.64\left(\mathrm{q}, 1 \mathrm{H}, J=7.2 \mathrm{~Hz}, \mathrm{CH}_{3} \mathrm{CH}\right), 6.96-6.97(\mathrm{dd}, 1 \mathrm{H}, J=8.7 \mathrm{~Hz}$, $J=2.4 \mathrm{~Hz}, \mathrm{CH} \mathrm{Ar}), 7.38$ (d, $1 \mathrm{H}, J=2.4 \mathrm{~Hz}, \mathrm{CH} \mathrm{Ar}), 7.60(\mathrm{~d}, 1 \mathrm{H}$, $J=8.7 \mathrm{~Hz}, \mathrm{CH} \mathrm{Ar}) ;{ }^{13} \mathrm{C}$ NMR $\left(\mathrm{CDCl}_{3}\right) \delta 14.3\left(\mathrm{CH}_{3} \mathrm{CH}_{2}\right), 18.2$ $\left(\mathrm{CH}_{3} \mathrm{CH}\right), 45.4\left(\mathrm{CH}_{3} \mathrm{CH}\right), 55.8\left(\mathrm{OCH}_{3}\right), 62.0\left(\mathrm{CH}_{2} \mathrm{CH}_{3}\right), 104.9$, 114.6, and 121.4 ( $\mathrm{CH} \mathrm{Ar}), 127.4,154.4$, and 159.1 ( $C \mathrm{Ar}), 165.5$ $(=C-\mathrm{S}), 171.9(C=\mathrm{O})$. Anal. $\left(\mathrm{C}_{13} \mathrm{H}_{15} \mathrm{NO}_{3} \mathrm{~S}_{2}\right) \mathrm{C}, \mathrm{H}, \mathrm{N}$.

Ethyl 2-[(6-Bromo-1,3-benzothiazol-2-yl)thio]propanoate [( rac $)$ 11p]. Yellowish oil, 52\% yield. IR (KBr) $1741 \mathrm{~cm}^{-1} ;{ }^{1} \mathrm{H}$ NMR
$\left(\mathrm{CDCl}_{3}\right) \delta 1.25\left(\mathrm{t}, 3 \mathrm{H}, J=7.2 \mathrm{~Hz}, \mathrm{CH}_{3} \mathrm{CH}_{2}\right), 1.70(\mathrm{~d}, 3 \mathrm{H}$, $\left.\mathrm{CH}_{3} \mathrm{CH}\right), 4.22\left(\mathrm{q}, 2 \mathrm{H}, J=7.2 \mathrm{~Hz}, \mathrm{CH}_{2} \mathrm{CH}_{3}\right), 4.66$ (q, $1 \mathrm{H}, J=$ $\left.7.2 \mathrm{~Hz}, \mathrm{CHCH}_{3}\right), 7.51(\mathrm{dd}, 1 \mathrm{H}, J=8.4 \mathrm{~Hz}, J=1.8 \mathrm{~Hz}, \mathrm{CH} \mathrm{Ar})$, $7.70(\mathrm{~d}, 1 \mathrm{H}, J=8.4 \mathrm{~Hz}, \mathrm{CH} \mathrm{Ar}), 7.88(\mathrm{~d}, 1 \mathrm{H}, J=1.8 \mathrm{~Hz}, \mathrm{CH} \mathrm{Ar})$; ${ }^{13} \mathrm{C} \mathrm{NMR}\left(\mathrm{CDCl}_{3}\right) \delta 14.3\left(\mathrm{CH}_{3} \mathrm{CH}_{2}\right), 18.1\left(\mathrm{CH}_{3} \mathrm{CH}\right), 45.4(\mathrm{CH})$, $62.1\left(\mathrm{CH}_{2} \mathrm{CH}_{3}\right), 118.1$ ( $\left.\mathrm{C} \mathrm{Ar}\right), 123.0,123.8$, and 129.7 ( $\left.\mathrm{CH} \mathrm{Ar}\right)$, 137.3, 152.1, and 165.4 (C Ar), 171.6 $(C=\mathrm{O})$. Anal. $\left(\mathrm{C}_{12} \mathrm{H}_{12^{-}}\right.$ $\left.\mathrm{BrNO}_{2} \mathrm{~S}_{2}\right) \mathrm{C}, \mathrm{H}, \mathrm{N}$.

Ethyl 2-[(6-Ethoxy-1,3-benzothiazol-2-yl)thio]propanoate [(rac)11q]. Yellowish oil, $47 \%$ yield. IR (KBr) $1734 \mathrm{~cm}^{-1} ;{ }^{1} \mathrm{H}$ NMR $\left(\mathrm{CDCl}_{3}\right) \delta 1.24\left(\mathrm{t}, 3 \mathrm{H}, J=7.2 \mathrm{~Hz}, \mathrm{CH}_{3} \mathrm{CH}_{2} \mathrm{O}\right), 1.43(\mathrm{t}, 3 \mathrm{H}, J=$ $7.2 \mathrm{~Hz}, \mathrm{CH}_{3} \mathrm{CH}_{2} \mathrm{OAr}$ ), 1.68 (d, 3H, $\mathrm{CH}_{3} \mathrm{CH}$ ), 4.05 (q, 2H, $J=$ $\left.7.2 \mathrm{~Hz}, \mathrm{OCH}_{2} \mathrm{CH}_{3}\right), 4.19\left(\mathrm{~m}, 2 \mathrm{H}, \mathrm{ArOCH}_{2} \mathrm{CH}_{3}\right), 4.56$ (q, 2H, $J=$ $\left.7.2 \mathrm{~Hz}, \mathrm{CHCH}_{3}\right), 7.00(\mathrm{dd}, 1 \mathrm{H}, J=8.7 \mathrm{~Hz}, J=2.4 \mathrm{~Hz}, \mathrm{CH} \mathrm{Ar})$, $7.21(\mathrm{~d}, 1 \mathrm{H}, J=2.4 \mathrm{~Hz}, \mathrm{CH} \mathrm{Ar}), 7.75(\mathrm{~d}, 1 \mathrm{H}, J=8.7 \mathrm{~Hz}, \mathrm{CH} \mathrm{Ar})$; ${ }^{13} \mathrm{C} \mathrm{NMR}\left(\mathrm{CDCl}_{3}\right) \delta 14.3\left(\mathrm{CH}_{3} \mathrm{CH}_{2} \mathrm{O}\right), 15.0\left(\mathrm{CH}_{3} \mathrm{CH}_{2} \mathrm{OAr}\right), 18.1$ $\left(\mathrm{CH}_{3} \mathrm{CH}\right), 45.5\left(\mathrm{CHCH}_{3}\right), 62.0\left(\mathrm{OCH}_{2} \mathrm{CH}_{3}\right), 64.3\left(\mathrm{ArOCH}_{2} \mathrm{CH}_{3}\right)$, 104.8, 115.7, and 122.6 (CH Ar), 137.3, 147.8, 156.8, and 160.7 $(C \operatorname{Ar}), 171.9(C=\mathrm{O})$. Anal. $\left(\mathrm{C}_{14} \mathrm{H}_{17} \mathrm{NO}_{3} \mathrm{~S}_{2}\right) \mathrm{C}, \mathrm{H}, \mathrm{N}$.

Ethyl 2-[(5-Chloro-1,3-benzothiazol-2-yl)thio]pentanoate [(rac)11r]. Colorless oil, $63 \%$ yield. IR (KBr) $1731 \mathrm{~cm}^{-1} ;{ }^{1} \mathrm{H}$ NMR $\left(\mathrm{CDCl}_{3}\right) \delta 0.97\left(\mathrm{t}, 3 \mathrm{H}, J=7.2 \mathrm{~Hz}, \mathrm{CH}_{3} \mathrm{CH}_{2}\right), 1.26(\mathrm{t}, 3 \mathrm{H}, J=$ $\left.6.9 \mathrm{~Hz}, \mathrm{CH}_{3} \mathrm{CH}_{2} \mathrm{O}\right), 1.45-1.53\left(\mathrm{~m}, 2 \mathrm{H}, \mathrm{CH}_{2} \mathrm{CH}_{3}\right), 1.88-2.10(\mathrm{~m}$, $\left.2 \mathrm{H}, \mathrm{CH}_{2} \mathrm{CH}\right), 4.23\left(\mathrm{dq}, 2 \mathrm{H}, J=7.2 \mathrm{~Hz}, \mathrm{OCH}_{2} \mathrm{CH}_{3}\right), 4.62(\mathrm{t}, 1 \mathrm{H}$, $\left.J=7.2 \mathrm{~Hz}, \mathrm{CHCH}_{2}\right), 7.27(\mathrm{dd}, 1 \mathrm{H}, J=8.7 \mathrm{~Hz}, J=2.1 \mathrm{~Hz}$, CH Ar), $7.65(\mathrm{~d}, 1 \mathrm{H}, J=8.7 \mathrm{~Hz}, \mathrm{CH} \mathrm{Ar}), 7.83(\mathrm{~d}, 1 \mathrm{H}, J=2.1 \mathrm{~Hz}$, $\mathrm{CH} \mathrm{Ar}) ;{ }^{13} \mathrm{C} \mathrm{NMR}\left(\mathrm{CDCl}_{3}\right) \delta 13.8\left(\mathrm{CH}_{3} \mathrm{CH}_{2}\right), 14.3\left(\mathrm{CH}_{3} \mathrm{CH}_{2} \mathrm{O}\right)$, $20.5\left(\mathrm{CH}_{2} \mathrm{CH}_{3}\right), 34.2\left(\mathrm{CH}_{2} \mathrm{CH}\right), 50.3(\mathrm{CH}), 61.9\left(\mathrm{OCH}_{2}\right), 121.8$ and 125.0 ( $\mathrm{CH} \mathrm{Ar}), 132.3,133.9,154.0$, and $167.2(C \mathrm{Ar}), 171.4$ $(C=\mathrm{O})$. Anal. $\left(\mathrm{C}_{14} \mathrm{H}_{16} \mathrm{ClNO}_{2} \mathrm{~S}_{2}\right) \mathrm{C}, \mathrm{H}, \mathrm{N}$.

Ethyl 2-[(6-Ethoxy-1,3-benzothiazol-2-yl)thio]pentanoate [( rac $)$ 11s]. Yellowish oil, 54\% yield. IR (KBr) $1732 \mathrm{~cm}^{-1} ;{ }^{1} \mathrm{H}$ NMR $\left(\mathrm{CDCl}_{3}\right) \delta 0.96\left(\mathrm{t}, 3 \mathrm{H}, J=7.2 \mathrm{~Hz}, \mathrm{CH}_{3} \mathrm{CH}_{2} \mathrm{CH}_{2}\right), 1.24(\mathrm{t}, 3 \mathrm{H}, J=$ $6.9 \mathrm{~Hz}, \mathrm{CH}_{3} \mathrm{CH}_{2} \mathrm{O}$ ), $1.43\left(\mathrm{t}, 3 \mathrm{H}, J=6.9 \mathrm{~Hz}, \mathrm{CH}_{3} \mathrm{CH}_{2} \mathrm{OAr}\right.$ ), 1.46-1.57 (m, 2H, $\left.\mathrm{CH}_{3} \mathrm{CH}_{2} \mathrm{CH}_{2}\right), 1.86-1.98\left(\mathrm{~m}, 2 \mathrm{H}, \mathrm{CH}_{3} \mathrm{CH}_{2}-\right.$ $\left.\mathrm{CH}_{2}\right), 4.05\left(\mathrm{q}, 2 \mathrm{H}, J=6.9 \mathrm{~Hz}, \mathrm{OCH}_{2} \mathrm{CH}_{3}\right), 4.20(\mathrm{dq}, 2 \mathrm{H}$, $\left.\mathrm{ArOCH}_{2} \mathrm{CH}_{3}\right), 4.49$ (t, $\left.1 \mathrm{H}, J=7.2 \mathrm{~Hz}, \mathrm{CHCH}_{2}\right), 7.00$ (dd, $1 \mathrm{H}$, $J=9.0 \mathrm{~Hz}, J=2.4 \mathrm{~Hz}, \mathrm{CHAr}), 7.21(\mathrm{~d}, 1 \mathrm{H}, J=2.4 \mathrm{~Hz}, \mathrm{CHAr})$, $7.74(\mathrm{~d}, 1 \mathrm{H}, J=9.0 \mathrm{~Hz}, \mathrm{CH} \mathrm{Ar}) ;{ }^{13} \mathrm{C} \mathrm{NMR}\left(\mathrm{CDCl}_{3}\right) \delta 13.8$ $\left(\mathrm{CH}_{3} \mathrm{CH}_{2} \mathrm{CH}_{2}\right), 14.3\left(\mathrm{CH}_{3} \mathrm{CH}_{2} \mathrm{O}\right), 15.0\left(\mathrm{CH}_{3} \mathrm{CH}_{2} \mathrm{OAr}\right), 20.6$ $\left(\mathrm{CH}_{2} \mathrm{CH}_{2} \mathrm{CH}_{3}\right), \quad 34.3\left(\mathrm{CH}_{2} \mathrm{CH}_{2} \mathrm{CH}_{3}\right), \quad 50.5\left(\mathrm{CHCH}_{2}\right), 61.8$ $\left(\mathrm{OCH}_{2} \mathrm{CH}_{3}\right), 64.3\left(\mathrm{ArOCH}_{2} \mathrm{CH}_{3}\right), 104.8,115.7$, and 122.6 $(C \mathrm{H} \mathrm{Ar}), 137.3,147.7,156.8$, and $161.0(C \mathrm{Ar}), 171.7(C=\mathrm{O})$. Anal. $\left(\mathrm{C}_{16} \mathrm{H}_{21} \mathrm{NO}_{3} \mathrm{~S}_{2}\right) \mathrm{C}, \mathrm{H}, \mathrm{N}$.

Ethyl 2-[(5-Chloro-1,3-benzothiazol-2-yl)thio]octanoate [(rac)11t]. Yellowish oil, $55 \%$ yield. IR (KBr) $1732 \mathrm{~cm}^{-1} ;{ }^{1} \mathrm{H}$ NMR $\left(\mathrm{CDCl}_{3}\right) \delta 0.87\left(\mathrm{t}, 3 \mathrm{H}, J=7.2 \mathrm{~Hz}, \mathrm{CH}_{3} \mathrm{CH}_{2}\right), 1.26(\mathrm{t}, 3 \mathrm{H}, J=$ $\left.7.2 \mathrm{~Hz}, \mathrm{CH}_{3} \mathrm{CH}_{2} \mathrm{O}\right), 1.28-1.50\left(\mathrm{~m}, 8 \mathrm{H}, \mathrm{CH}_{2}\right), 1.94-2.06(\mathrm{~m}, 2 \mathrm{H}$, $\left.\mathrm{CH}_{2}\right), 4.22$ and $4.23\left(\mathrm{dq}, 2 \mathrm{H}, J=7.2 \mathrm{~Hz}, \mathrm{OCH}_{2} \mathrm{CH}_{3}\right), 4.60(\mathrm{t}, 1 \mathrm{H}$, $J=7.2 \mathrm{~Hz}, \mathrm{CHS}), 7.27(\mathrm{dd}, 1 \mathrm{H}, J=8.7 \mathrm{~Hz}, J=2.1 \mathrm{~Hz}, \mathrm{CH} \mathrm{Ar})$, $7.65(\mathrm{~d}, 1 \mathrm{H}, J=8.7 \mathrm{~Hz}, \mathrm{CH} \mathrm{Ar}), 7.83(\mathrm{~d}, 1 \mathrm{H}, J=2.1 \mathrm{~Hz}, \mathrm{CH} \mathrm{Ar}) ;$ ${ }^{13} \mathrm{C} \mathrm{NMR}\left(\mathrm{CDCl}_{3}\right) \delta 14.2\left(\mathrm{CH}_{3} \mathrm{CH}_{2}\right), 14.4\left(\mathrm{CH}_{3} \mathrm{CH}_{2} \mathrm{O}\right), 22.7$, 27.1, 28.9, 31.7, and $32.2\left(\mathrm{CH}_{2}\right), 50.5(\mathrm{CH}), 62.0\left(\mathrm{OCH}_{2}\right), 121.8$, 121.9, and 125.0 ( $\mathrm{CH} \mathrm{Ar}), 132.3,133.9,154.0$, and 167.2 ( $\mathrm{C} \mathrm{Ar}$, $171.4(C=\mathrm{O})$. Anal. $\left(\mathrm{C}_{17} \mathrm{H}_{22} \mathrm{ClNO}_{2} \mathrm{~S}_{2}\right) \mathrm{C}, \mathrm{H}, \mathrm{N}$.

Ethyl [(5-Chloro-1,3-benzothiazol-2-yl)thio] (phenyl)acetate [( rac $)$ 11u]. Colorless oil, $64 \%$ yield. IR (KBr) $1738 \mathrm{~cm}^{-1} ;{ }^{1} \mathrm{H}$ NMR $\left(\mathrm{CDCl}_{3}\right) \delta 1.26\left(\mathrm{t}, 3 \mathrm{H}, J=6.9 \mathrm{~Hz}, \mathrm{CH}_{3} \mathrm{CH}_{2}\right), 4.19$ and $4.28(\mathrm{dq}, 2 \mathrm{H}$, $\left.J=6.9 \mathrm{~Hz}, \mathrm{OCH}_{2} \mathrm{CH}_{3}\right), 5.76(\mathrm{~s}, 1 \mathrm{H}, \mathrm{CHS}), 7.25-7.38(\mathrm{~m}, 5 \mathrm{H}$, $\mathrm{C} H \mathrm{Ar}), 7.52(\mathrm{dd}, 1 \mathrm{H}, J=8.4 \mathrm{~Hz}, J=1.8 \mathrm{~Hz}, \mathrm{CH} \mathrm{Ar}), 7.64(\mathrm{~d}, 1 \mathrm{H}$, $J=8.4 \mathrm{~Hz}, \mathrm{CH} \mathrm{Ar}), 7.83(\mathrm{~d}, 1 \mathrm{H}, J=1.8 \mathrm{~Hz}, \mathrm{CH} \mathrm{Ar}) ;{ }^{13} \mathrm{C} \mathrm{NMR}$ $\left(\mathrm{CDCl}_{3}\right) \delta 14.3\left(\mathrm{CH}_{3} \mathrm{CH}_{2}\right), 54.8(\mathrm{CHS}), 62.5\left(\mathrm{OCH}_{2}\right), 121.7,121.9$, 125.0, 128.7, 129.1, and 129.2 ( $\mathrm{CH} \mathrm{Ar}), 132.3,133.9,153.9$, and 167.0 ( $C$ Ar), $169.6(C=\mathrm{O})$. Anal. $\left(\mathrm{C}_{17} \mathrm{H}_{14} \mathrm{ClNO}_{2} \mathrm{~S}_{2}\right) \mathrm{C}, \mathrm{H}, \mathrm{N}$.

General Procedure for the Preparation of Acids $12 \mathrm{c}-\mathrm{k}$ and $\mathrm{rac}$ 12l-u. $\mathrm{NaOH}(1 \mathrm{~N}, 3.9 \mathrm{mmol})$ was added to esters $\mathbf{1 1} \mathbf{c}-\mathbf{k}$ and rac-11l-u $(3.0 \mathrm{mmol})$ in EtOH $(20 \mathrm{~mL})$, and the mixture was stirred at room temperature for $10-15 \mathrm{~h}$. The solvent was removed under reduced pressure, and the residue was poured into water $(20 \mathrm{~mL})$ and acidified with concentrated $\mathrm{HCl}$ at $0{ }^{\circ} \mathrm{C}$. 
The aqueous layer was extracted with dichloromethane $(3 \times$ $20 \mathrm{~mL}$ ), and the organic layer was dried over $\mathrm{Na}_{2} \mathrm{SO}_{4}$ and concentrated under reduced pressure. The residue was purified by crystallization or by column chromatography on silica gel (eluent cyclohexane/ethyl acetate, 1:1, or dichloromethane/ methanol, 9:1), affording desired acids with good yields.

2-[(5-Bromo-1,3-benzothiazol-2-yl)thio]-2-methylpropanoic Acid (12c). White solid, $46 \%$ yield, $\mathrm{mp} 121-123^{\circ} \mathrm{C}$. IR (KBr) $1710 \mathrm{~cm}^{-1}$; ${ }^{1} \mathrm{H}$ NMR (DMSO) $\delta 1.71\left(\mathrm{~s}, 6 \mathrm{H}, \mathrm{C}\left(\mathrm{CH}_{3}\right)_{2}\right), 7.48-7.51(\mathrm{dd}, 1 \mathrm{H}, J=$ $8.7 \mathrm{~Hz}, J=2.7 \mathrm{~Hz}, \mathrm{CH} \mathrm{Ar}), 7.91(\mathrm{~d}, 1 \mathrm{H}, J=2.7 \mathrm{~Hz}, \mathrm{C} H \mathrm{Ar}), 8.04$ $(\mathrm{d}, 1 \mathrm{H}, J=8.7 \mathrm{~Hz}, \mathrm{CH} \mathrm{Ar}) ;{ }^{13} \mathrm{C}$ NMR $\left.(\mathrm{DMSO}) \delta 27.7\left(\mathrm{C} \mathrm{CH}_{3}\right)_{2}\right)$, $60.8\left(\mathrm{C}\left(\mathrm{CH}_{3}\right)_{2}\right), 119.5(\mathrm{CBr}), 123.7,124.3$, and $127.7(\mathrm{CH} \mathrm{Ar}), 134.8$ and $155.0(C \mathrm{Ar}), 169.9(=C-\mathrm{S}), 176.1(C=\mathrm{O})$. Anal. $\left(\mathrm{C}_{11} \mathrm{H}_{10^{-}}\right.$ $\left.\mathrm{BrNO}_{2} \mathrm{~S}_{2}\right) \mathrm{C}, \mathrm{H}, \mathrm{N}$.

2-[(5-Cyano-1,3-benzothiazol-2-yl)thio]-2-methylpropanoic Acid (12d). White solid, $61 \%$ yield, mp $265^{\circ} \mathrm{C}(\mathrm{dec})$. IR (KBr) 2230, $1712 \mathrm{~cm}^{-1} ;{ }^{1} \mathrm{H}$ NMR (DMSO) $\delta 1.74\left(\mathrm{~s}, 6 \mathrm{H}, \mathrm{C}\left(\mathrm{CH}_{3}\right)_{2}\right), 7.72-7.76$ $(\mathrm{dd}, 1 \mathrm{H}, J=8.4 \mathrm{~Hz}, J=1.8 \mathrm{~Hz}, \mathrm{C} H \mathrm{Ar}), 8.20(\mathrm{~d}, 1 \mathrm{H}, J=8.4 \mathrm{~Hz}$, $\mathrm{CH} \mathrm{Ar}), 8.34(\mathrm{~d}, 1 \mathrm{H}, J=1.8 \mathrm{~Hz}, \mathrm{CH} \mathrm{Ar}),{ }^{13} \mathrm{C}$ NMR (DMSO) $\delta$ $27.6\left(\mathrm{C}\left(\mathrm{CH}_{3}\right)_{2}\right), 60.1\left(\mathrm{C}\left(\mathrm{CH}_{3}\right)_{2}\right), 109.5(\mathrm{CCN}), 123.8,125.8$, and 127.7 ( $C H$ Ar), 140.8 and 153.1 ( $C$ Ar), $170.6(=C-\mathrm{S}), 175.5$ $(C=\mathrm{O})$. Anal. $\left(\mathrm{C}_{12} \mathrm{H}_{10} \mathrm{~N}_{2} \mathrm{O}_{2} \mathrm{~S}_{2}\right) \mathrm{C}, \mathrm{H}, \mathrm{N}$.

2-[(5-Trifluoromethyl-1,3-benzothiazol-2-yl)thio]-2-methylpropanoic Acid (12e). White needles, $48 \%$ yield, mp $147-149^{\circ} \mathrm{C}$. IR (KBr) $1709 \mathrm{~cm}^{-1} ;{ }^{1} \mathrm{H}$ NMR $\left(\mathrm{CD}_{3} \mathrm{OD}\right) \delta 1.78\left(\mathrm{~s}, 6 \mathrm{H}, \mathrm{C}\left(\mathrm{CH}_{3}\right)_{2}\right)$, $7.61(\mathrm{dd}, 1 \mathrm{H}, J=9.0 \mathrm{~Hz}, J=1.8 \mathrm{~Hz}, \mathrm{CH} \mathrm{Ar}), 8.06(\mathrm{~d}, 1 \mathrm{H}, J=$ $9.0 \mathrm{~Hz}, \mathrm{CH} \mathrm{Ar}), 8.14$ (d, $1 \mathrm{H}, J=1.8 \mathrm{~Hz}, \mathrm{CH} \mathrm{Ar}) ;{ }^{13} \mathrm{C}$ NMR $\left(\mathrm{CD}_{3} \mathrm{OD}\right) \delta 25.8\left(\mathrm{C}\left(\mathrm{CH}_{3}\right)_{2}\right), 55.1\left(\mathrm{C}\left(\mathrm{CH}_{3}\right)_{2}\right), 118.4,120.9$, and $122.2(\mathrm{CH} \mathrm{Ar}), 128.4\left(\mathrm{CF}_{3}\right), 139.7,144.6,152.9$, and 167.2 (C Ar), $175.9(C=\mathrm{O})$. Anal. $\left(\mathrm{C}_{12} \mathrm{H}_{10} \mathrm{~F}_{3} \mathrm{NO}_{2} \mathrm{~S}_{2}\right) \mathrm{C}, \mathrm{H}, \mathrm{N}$.

2-[(5-Methoxy-1,3-benzothiazol-2-yl)thio]-2-methylpropanoic Acid (12f). Yellowish solid (from cyclohexane), 58\% yield, $\mathrm{mp}$ $131-133^{\circ} \mathrm{C}$. IR (KBr) $1710 \mathrm{~cm}^{-1}$; ${ }^{1} \mathrm{H}$ NMR $\left(\mathrm{CD}_{3} \mathrm{OD}\right) \delta 1.71(\mathrm{~s}$, $\left.6 \mathrm{H}, \mathrm{C}\left(\mathrm{CH}_{3}\right)_{2}\right), 3.86\left(\mathrm{~s}, 3 \mathrm{H}, \mathrm{OCH}_{3}\right), 7.01-7.05(\mathrm{dd}, 1 \mathrm{H}, J=$ $8.7 \mathrm{~Hz}, J=2.7 \mathrm{~Hz}, \mathrm{CH} \mathrm{Ar}), 7.44(\mathrm{~d}, 1 \mathrm{H}, J=2.7 \mathrm{~Hz}, \mathrm{CH} \mathrm{Ar})$, $7.73(\mathrm{~d}, 1 \mathrm{H}, J=8.7 \mathrm{~Hz}, \mathrm{CH} \mathrm{Ar}) ;{ }^{13} \mathrm{C} \mathrm{NMR}\left(\mathrm{CD}_{3} \mathrm{OD}\right) \delta 25.6$ $\left(\mathrm{C}\left(\mathrm{CH}_{3}\right)_{2}\right), 54.1\left(\mathrm{C}\left(\mathrm{CH}_{3}\right)_{2}\right), 54.8\left(\mathrm{OCH}_{3}\right), 104.5,115.3$, and 121.4 $(C \mathrm{H} \mathrm{Ar}), 128.3,154.5$, and $159.5(C \mathrm{Ar}), 163.6(=C-\mathrm{S}), 175.2$ $(C=\mathrm{O})$. Anal. $\left(\mathrm{C}_{12} \mathrm{H}_{13} \mathrm{NO}_{3} \mathrm{~S}_{2}\right) \mathrm{C}, \mathrm{H}, \mathrm{N}$.

2-[(6-Chloro-1,3-benzothiazol-2-yl)thio]-2-methylpropanoic Acid (12g). White solid, $45 \%$ yield, mp $140-141^{\circ} \mathrm{C}$. IR (KBr) $1714 \mathrm{~cm}^{-1}$; ${ }^{1} \mathrm{H}$ NMR $\left(\mathrm{CDCl}_{3}\right) \delta 1.75\left(\mathrm{~s}, 6 \mathrm{H}, \mathrm{C}\left(\mathrm{CH}_{3}\right)_{2}\right), 7.42(\mathrm{dd}, 1 \mathrm{H}, J=$ $9.0 \mathrm{~Hz}, J=1.8 \mathrm{~Hz}, \mathrm{CH} \mathrm{Ar}), 7.76(\mathrm{~d}, 1 \mathrm{H}, J=1.8 \mathrm{~Hz}, \mathrm{CH} \mathrm{Ar}), 7.81$

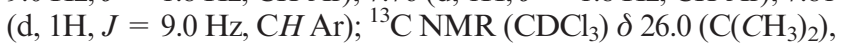

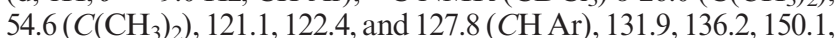
and $166.4(C \mathrm{Ar}), 174.3(C=\mathrm{O})$. Anal. $\left(\mathrm{C}_{11} \mathrm{H}_{10} \mathrm{ClNO}_{2} \mathrm{~S}_{2}\right) \mathrm{C}, \mathrm{H}, \mathrm{N}$.

2-[(6-Bromo-1,3-benzothiazol-2-yl)thio]-2-methylpropanoic Acid (12h). White solid, $51 \%$ yield, $\mathrm{mp} 118-120^{\circ} \mathrm{C}$. IR (KBr) $1716 \mathrm{~cm}^{-1}$; ${ }^{1} \mathrm{H}$ NMR $\left(\mathrm{CDCl}_{3}\right) \delta 1.71\left(\mathrm{~s}, 6 \mathrm{H}, \mathrm{C}\left(\mathrm{CH}_{3}\right)_{2}\right), 7.49(\mathrm{dd}, 1 \mathrm{H}, J=$ $8.7 \mathrm{~Hz}, J=1.8 \mathrm{~Hz}, \mathrm{CH} \mathrm{Ar}), 7.71(\mathrm{~d}, 1 \mathrm{H}, J=8.7 \mathrm{~Hz}, \mathrm{CH} \mathrm{Ar}), 7.85$

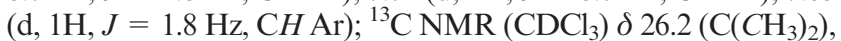

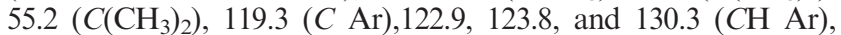
136.9, 150.8, and $165.9(C \mathrm{Ar}), 174.5(C=\mathrm{O})$. Anal. $\left(\mathrm{C}_{11} \mathrm{H}_{10^{-}}\right.$ $\left.\mathrm{BrNO}_{2} \mathrm{~S}_{2}\right) \mathrm{C}, \mathrm{H}, \mathrm{N}$.

2-[(6-Cyano-1,3-benzothiazol-2-yl)thio]-2-methylpropanoic acid (12i). White solid, $37 \%$ yield, $\mathrm{mp} 170-172{ }^{\circ} \mathrm{C}$. IR (KBr) 2230, $1704 \mathrm{~cm}^{-1} ;{ }^{1} \mathrm{H}$ NMR $\left(\mathrm{CD}_{3} \mathrm{OD}\right) \delta 1.79\left(\mathrm{~s}, 6 \mathrm{H}, \mathrm{C}\left(\mathrm{CH}_{3}\right)_{2}\right), 7.73(\mathrm{dd}$, $1 \mathrm{H}, J=8.4 \mathrm{~Hz}, J=1.5 \mathrm{~Hz}, \mathrm{CH} \mathrm{Ar}), 7.94(\mathrm{~d}, 1 \mathrm{H}, J=8.4 \mathrm{~Hz}$, $\mathrm{CH} \mathrm{Ar}), 8.31(\mathrm{~d}, 1 \mathrm{H}, J=1.5 \mathrm{~Hz}, \mathrm{CH} \mathrm{Ar}) ;{ }^{13} \mathrm{C} \mathrm{NMR}\left(\mathrm{CD}_{3} \mathrm{OD}\right) \delta$ $25.7\left(\mathrm{C}\left(\mathrm{CH}_{3}\right)_{2}\right), 55.3\left(\mathrm{C}\left(\mathrm{CH}_{3}\right)_{2}\right), 107.8(\mathrm{C} \mathrm{Ar}), 118.4(\mathrm{CN}), 122.2$, 126.1, and 129.5 (CH Ar), 136.3, 155.6, and 170.1 (C Ar), 175.5 $(C=\mathrm{O})$. Anal. $\left(\mathrm{C}_{12} \mathrm{H}_{10} \mathrm{~N}_{2} \mathrm{O}_{2} \mathrm{~S}_{2}\right) \mathrm{C}, \mathrm{H}, \mathrm{N}$.

2-[(6-Trifluoromethyl-1,3-benzothiazol-2-yl)thio]-2-methylpropanoic Acid (12j). White needles, $42 \%$ yield, $\mathrm{mp} 149-151^{\circ} \mathrm{C}$. IR (KBr) $1709 \mathrm{~cm}^{-1} ;{ }^{1} \mathrm{H}$ NMR $\left(\mathrm{CD}_{3} \mathrm{OD}\right) \delta 1.78\left(\mathrm{~s}, 6 \mathrm{H}, \mathrm{C}\left(\mathrm{CH}_{3}\right)_{2}\right)$, $7.68(\mathrm{dd}, 1 \mathrm{H}, J=9.0 \mathrm{~Hz}, J=1.8 \mathrm{~Hz}, \mathrm{CH} \mathrm{Ar}), 7.96(\mathrm{~d}, 1 \mathrm{H}, J=$ $9.0 \mathrm{~Hz}, \mathrm{CH} \mathrm{Ar}), 8.21$ (d, $1 \mathrm{H}, J=1.8 \mathrm{~Hz}, \mathrm{CH} \mathrm{Ar}) ;{ }^{13} \mathrm{C}$ NMR $\left(\mathrm{CD}_{3} \mathrm{OD}\right) \delta 26.2\left(\mathrm{C}\left(\mathrm{CH}_{3}\right)_{2}\right), 57.1\left(\mathrm{C}_{\left.\left(\mathrm{CH}_{3}\right)_{2}\right), 118.8,121.9 \text {, and }}\right.$ 122.9 ( $C \mathrm{H} \mathrm{Ar}), 126.3\left(\mathrm{CF}_{3}\right), 129.3,136.1,155.4$, and 169.6 $(C \mathrm{Ar}), 177.9(C=\mathrm{O})$. Anal. $\left(\mathrm{C}_{12} \mathrm{H}_{10} \mathrm{~F}_{3} \mathrm{NO}_{2} \mathrm{~S}_{2}\right) \mathrm{C}, \mathrm{H}, \mathrm{N}$.
2-[(6-Ethoxy-1,3-benzothiazol-2-yl)thio]-2-methylpropanoic Acid (12k). Yellowish solid, $46 \%$ yield, mp $124-126{ }^{\circ} \mathrm{C}$. IR ( $\mathrm{KBr}$ ) $1716 \mathrm{~cm}^{-1} ;{ }^{1} \mathrm{H}$ NMR $\left(\mathrm{CD}_{3} \mathrm{OD}\right) \delta 1.40(\mathrm{t}, 3 \mathrm{H}, J=7.2 \mathrm{~Hz}$, $\left.\mathrm{CH}_{3} \mathrm{CH}_{2} \mathrm{OAr}\right), 1.66\left(\mathrm{~s}, 6 \mathrm{H}, \mathrm{C}\left(\mathrm{CH}_{3}\right)_{2}\right), 4.06(\mathrm{q}, 2 \mathrm{H}, J=7.2 \mathrm{~Hz}$, $\mathrm{ArOCH}_{2} \mathrm{CH}_{3}$ ), $7.06(\mathrm{dd}, 1 \mathrm{H}, J=9.3 \mathrm{~Hz}, J=2.4 \mathrm{~Hz}, \mathrm{CH} \mathrm{Ar}), 7.39$ $(\mathrm{d}, 1 \mathrm{H}, J=2.4 \mathrm{~Hz}, \mathrm{CHAr}), 7.78(\mathrm{~d}, 1 \mathrm{H}, J=9.3 \mathrm{~Hz}, \mathrm{CH} \mathrm{Ar}) ;{ }^{13} \mathrm{C}$

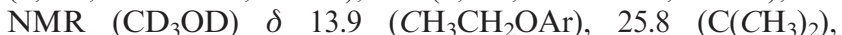
$54.5\left(\mathrm{C}\left(\mathrm{CH}_{3}\right)_{2}\right), 64.0\left(\mathrm{ArOCH}_{2} \mathrm{CH}_{3}\right), 104.1,116.3$, and 122.7 ( $C \mathrm{H} \mathrm{Ar}), 138.6,147.5,157.7$, and 159.1 ( $C \mathrm{Ar}), 175.9(C=\mathrm{O})$. Anal. $\left(\mathrm{C}_{13} \mathrm{H}_{15} \mathrm{NO}_{3} \mathrm{~S}_{2}\right) \mathrm{C}, \mathrm{H}, \mathrm{N}$.

2-[(5-Chloro-1,3-benzothiazol-2-yl)thio]propanoic Acid [rac-(12l)]. White solid, $46 \%$ yield, $\mathrm{mp} 110-112^{\circ} \mathrm{C}$. IR (KBr) $1709 \mathrm{~cm}^{-1} ;{ }^{1} \mathrm{H}$ $\operatorname{NMR}\left(\mathrm{CD}_{3} \mathrm{OD}\right) \delta 0.16\left(\mathrm{~d}, 3 \mathrm{H}, J=6.9 \mathrm{~Hz}, \mathrm{CH}_{3} \mathrm{CH}\right), 3.02(\mathrm{q}, 1 \mathrm{H}$, $\left.J=6.9 \mathrm{~Hz}, \mathrm{CH}_{3} \mathrm{CH}\right), 5.73-5.76(\mathrm{dd}, 1 \mathrm{H}, J=8.7 \mathrm{~Hz}, J=1.8 \mathrm{CH}$ $\mathrm{Ar}), 6.22(\mathrm{~d}, 1 \mathrm{H}, J=1.8 \mathrm{~Hz}, \mathrm{CH} \mathrm{Ar}), 6.25(\mathrm{~d}, 1 \mathrm{H}, J=8.7 \mathrm{~Hz}, \mathrm{CH}$ $\mathrm{Ar}) ;{ }^{13} \mathrm{C} \mathrm{NMR}\left(\mathrm{CD}_{3} \mathrm{OD}\right) \delta 20.8\left(\mathrm{CH}_{3} \mathrm{CH}\right), 51.1\left(\mathrm{CH}_{3} \mathrm{CH}\right), 121.0$, 123.6, and $124.8(\mathrm{CH} \mathrm{Ar}), 131.6$ and $154.5(C \mathrm{Ar}), 133.9(\mathrm{CCl})$, $171.4(=C-\mathrm{S}), 173.4(C=\mathrm{O})$. Anal. $\left(\mathrm{C}_{10} \mathrm{H}_{8} \mathrm{ClNO}_{2} \mathrm{~S}_{2}\right) \mathrm{C}, \mathrm{H}, \mathrm{N}$.

2-[(5-Bromo-1,3-benzothiazol-2-yl)thio]propanoic Acid [rac- $(12 \mathrm{~m})]$. Yellow solid, $78 \%$ yield, mp $108-109^{\circ} \mathrm{C}$. IR $(\mathrm{KBr}) 1712 \mathrm{~cm}^{-1} ;{ }^{1} \mathrm{H}$ NMR (DMSO) $\delta 1.62\left(\mathrm{~d}, 3 \mathrm{H}, J=6.6 \mathrm{~Hz}, \mathrm{CH}_{3} \mathrm{CH}\right), 4.37(\mathrm{q}, 1 \mathrm{H}$, $\left.J=6.6 \mathrm{~Hz}, \mathrm{CH}_{3} \mathrm{CH}\right), 7.45-7.49(\mathrm{dd}, 1 \mathrm{H}, J=8.4 \mathrm{~Hz}, J=1.8 \mathrm{~Hz}$, $\mathrm{CH} \mathrm{Ar}), 7.92(\mathrm{~d}, 1 \mathrm{H}, J=8.4 \mathrm{~Hz}, \mathrm{CH} \mathrm{Ar}), 7.99(\mathrm{~d}, 1 \mathrm{H}, J=1.8 \mathrm{~Hz}$, $\mathrm{CH} \mathrm{Ar}) ;{ }^{13} \mathrm{C}$ NMR (DMSO) $\delta 20.6\left(\mathrm{CH}_{3} \mathrm{CH}\right), 50.6\left(\mathrm{CH}_{3} \mathrm{CH}\right), 119.7$ $(C \mathrm{Br}), 123.9,124.0$, and 127.5 (CH Ar), 134.4 and 154.8(C Ar), 170.8 $(=C-\mathrm{S}), 173.5(C=\mathrm{O})$. Anal. $\left(\mathrm{C}_{10} \mathrm{H}_{8} \mathrm{BrNO}_{2} \mathrm{~S}_{2}\right) \mathrm{C}, \mathrm{H}, \mathrm{N}$.

2-[(5-Cyano-1,3-benzothiazol-2-yl)thio]propanoic Acid [rac-(12n)]. White solid, $66 \%$ yield, $\mathrm{mp} 124-125^{\circ} \mathrm{C}$. IR (KBr) $2233,1721 \mathrm{~cm}^{-1}$; ${ }^{1} \mathrm{H}$ NMR (DMSO) $\delta 1.63\left(\mathrm{~d}, 3 \mathrm{H}, J=6.9 \mathrm{~Hz}, \mathrm{CH}_{3} \mathrm{CH}\right), 4.45(\mathrm{q}, 1 \mathrm{H}$, $\left.J=6.9 \mathrm{~Hz}, \mathrm{CH}_{3} \mathrm{CH}\right), 7.70-7.73(\mathrm{dd}, 1 \mathrm{H}, J=8.1 \mathrm{~Hz}, J=1.5 \mathrm{~Hz}$, $\mathrm{CH} \mathrm{Ar}), 8.19(\mathrm{~d}, 1 \mathrm{H}, J=8.1 \mathrm{~Hz}, \mathrm{CH} \mathrm{Ar}), 8.29(\mathrm{~d}, 1 \mathrm{H}, J=1.5 \mathrm{~Hz}$, $\mathrm{CH} \mathrm{Ar}) ;{ }^{13} \mathrm{C}$ NMR (DMSO) $\delta 20.1\left(\mathrm{CH}_{3} \mathrm{CH}\right), 49.6\left(\mathrm{CH}_{3} \mathrm{CH}\right)$, $109.5(C \mathrm{CN}), 120.7(\mathrm{CN}), 123.9,125.3$, and $127.5(\mathrm{CH} \mathrm{Ar}), 140.6$ and $153.1(C \mathrm{Ar}), 171.2(=C-\mathrm{S}), 173.3(C=\mathrm{O})$. Anal. $\left(\mathrm{C}_{11} \mathrm{H}_{8^{-}}\right.$ $\left.\mathrm{N}_{2} \mathrm{O}_{2} \mathrm{~S}_{2}\right) \mathrm{C}, \mathrm{H}, \mathrm{N}$.

2-[(5-Methoxy1,3-benzothiazol-2-yl)thio]propanoic Acid [rac-(12o)]. White solid, $90 \%$ yield, mp $131-133{ }^{\circ} \mathrm{C}$. IR $(\mathrm{KBr})$ $1710 \mathrm{~cm}^{-1} ;{ }^{1} \mathrm{H}$ NMR $\left(\mathrm{CD}_{3} \mathrm{OD}\right) \delta 1.70(\mathrm{~d}, 3 \mathrm{H}, J=7.5 \mathrm{~Hz}$, $\left.\mathrm{CH}_{3} \mathrm{CH}\right), 3.84$ (s, $\left.3 \mathrm{H}, \mathrm{OCH}_{3}\right), 4.48\left(\mathrm{q}, 1 \mathrm{H}, J=7.5 \mathrm{~Hz}, \mathrm{CH}_{3} \mathrm{CH}\right)$, 6.93-6.97 (dd, $1 \mathrm{H}, J=8.7 \mathrm{~Hz}, J=2.4 \mathrm{~Hz}, \mathrm{CH} \mathrm{Ar}), 7.33(\mathrm{~d}, 1 \mathrm{H}$, $J=2.4 \mathrm{~Hz}, \mathrm{CH} \mathrm{Ar}), 7.67(\mathrm{~d}, 1 \mathrm{H}, J=8.7 \mathrm{~Hz}, \mathrm{CH} \mathrm{Ar}) ;{ }^{13} \mathrm{C} \mathrm{NMR}$ $\left(\mathrm{CD}_{3} \mathrm{OD}\right) \delta 18.9\left(\mathrm{CH}_{3} \mathrm{CH}\right), 49.3\left(\mathrm{CH}_{3} \mathrm{CH}\right), 54.8\left(\mathrm{OCH}_{3}\right), 104.0$, 113.8, and 121.2 ( $\mathrm{CH} \mathrm{Ar}), 126.6,154.4$, and 159.4 (C Ar), 155.8 $(=C-\mathrm{S}), 168.9(C=\mathrm{O})$. Anal. $\left(\mathrm{C}_{11} \mathrm{H}_{11} \mathrm{NO}_{3} \mathrm{~S}_{2}\right) \mathrm{C}, \mathrm{H}, \mathrm{N}$.

2-[(6-Bromo-1,3-benzothiazol-2-yl)thio]propanoic Acid [rac-(12p)]. White solid, $63 \%$ yield, mp $112-114{ }^{\circ} \mathrm{C}$. IR $(\mathrm{KBr}) 1718 \mathrm{~cm}^{-1} ;{ }^{1} \mathrm{H}$ NMR (DMSO) $\delta 1.61\left(\mathrm{~d}, 3 \mathrm{H}, J=7.2 \mathrm{~Hz}, \mathrm{CH}_{3} \mathrm{CH}\right), 4.45(\mathrm{q}, 1 \mathrm{H}$, $\left.J=7.2 \mathrm{~Hz}, \mathrm{CHCH}_{3}\right), 7.55(\mathrm{dd}, 1 \mathrm{H}, J=8.4 \mathrm{~Hz}, J=1.8 \mathrm{~Hz}, \mathrm{CHAr})$, $7.72(\mathrm{~d}, 1 \mathrm{H}, J=8.4 \mathrm{~Hz}, \mathrm{CH} \mathrm{Ar}), 8.24(\mathrm{~d}, 1 \mathrm{H}, J=1.8 \mathrm{~Hz}, \mathrm{CH} \mathrm{Ar})$; ${ }^{13} \mathrm{C}$ NMR (DMSO) $\delta 20.0\left(\mathrm{CH}_{3} \mathrm{CH}\right), 49.1(\mathrm{CH}), 117.4(\mathrm{C} \mathrm{Ar})$, 123.1, 124.9, and 130.0 ( $\mathrm{CH} \mathrm{Ar}), 137.2,152.5$, and 168.6 ( $C \mathrm{Ar}$ ), $173.3(C=\mathrm{O})$. Anal. $\left(\mathrm{C}_{10} \mathrm{H}_{8} \mathrm{BrNO}_{2} \mathrm{~S}_{2}\right) \mathrm{C}, \mathrm{H}, \mathrm{N}$.

2-[(6-Ethoxy-1,3-benzothiazol-2-yl)thio]propanoic Acid [rac(12q)]. White solid, 49\% yield, mp 90-91 ${ }^{\circ} \mathrm{C}$. IR (KBr) 1716 $\mathrm{cm}^{-1} ;{ }^{1} \mathrm{HNMR}\left(\mathrm{CDCl}_{3}\right) \delta 1.45\left(\mathrm{t}, 3 \mathrm{H}, J=6.9 \mathrm{~Hz}, \mathrm{CH}_{3} \mathrm{CH}_{2} \mathrm{OAr}\right)$, $1.64\left(\mathrm{~d}, 3 \mathrm{H}, \mathrm{CH}_{3} \mathrm{CH}\right), 4.07\left(\mathrm{q}, 2 \mathrm{H}, J=6.9 \mathrm{~Hz}, \mathrm{ArOCH}_{2} \mathrm{CH}_{3}\right)$, $4.32\left(\mathrm{q}, 2 \mathrm{H}, J=6.9 \mathrm{~Hz}, \mathrm{CHCH}_{3}\right), 7.06(\mathrm{dd}, 1 \mathrm{H}, J=9.0 \mathrm{~Hz}, J=$ $2.4 \mathrm{~Hz}, \mathrm{CH} \mathrm{Ar}), 7.23(\mathrm{~d}, 1 \mathrm{H}, J=2.4 \mathrm{~Hz}, \mathrm{CH} \mathrm{Ar}), 7.75(\mathrm{~d}, 1 \mathrm{H}$, $J=9.3 \mathrm{~Hz}, \mathrm{CH} \mathrm{Ar}) ;{ }^{13} \mathrm{C} \mathrm{NMR}\left(\mathrm{CDCl}_{3}\right) \delta 14.9\left(\mathrm{CH}_{3} \mathrm{CH}_{2} \mathrm{OAr}\right)$, $16.4\left(\mathrm{CH}_{3} \mathrm{CH}\right), 44.7\left(\mathrm{CHCH}_{3}\right), 64.4\left(\mathrm{ArOCH}_{2} \mathrm{CH}_{3}\right), 105.0,116.5$, and $121.7(\mathrm{CH} \mathrm{Ar}), 136.2,145.3,157.5$, and 160.5 (C Ar), 171.9 $(C=\mathrm{O})$. Anal. $\left(\mathrm{C}_{12} \mathrm{H}_{13} \mathrm{NO}_{3} \mathrm{~S}_{2}\right) \mathrm{C}, \mathrm{H}, \mathrm{N}$.

2-[(5-Chloro-1,3-benzothiazol-2-yl)thio]pentanoic Acid [rac(12r)]. White solid, 59\% yield, mp $100-101^{\circ} \mathrm{C}$. IR (KBr) 1718 $\mathrm{cm}^{-1} ;{ }^{1} \mathrm{H} \mathrm{NMR}\left(\mathrm{CDCl}_{3}\right) \delta 0.97\left(\mathrm{t}, 3 \mathrm{H}, J=7.2 \mathrm{~Hz}, \mathrm{CH}_{3} \mathrm{CH}_{2}\right)$, $1.51-1.61\left(\mathrm{~m}, 2 \mathrm{H}, \mathrm{CH}_{2} \mathrm{CH}_{3}\right), 1.83-2.19\left(\mathrm{~m}, 2 \mathrm{H}, \mathrm{CH}_{2} \mathrm{CH}\right), 4.35$ $(\mathrm{t}, 1 \mathrm{H}, J=7.2 \mathrm{~Hz}, \mathrm{CH}), 7.34(\mathrm{dd}, 1 \mathrm{H}, J=8.7 \mathrm{~Hz}, J=2.1 \mathrm{~Hz}$, $\mathrm{C} H \mathrm{Ar}), 7.69(\mathrm{~d}, 1 \mathrm{H}, J=8.7 \mathrm{~Hz}, \mathrm{CH} \mathrm{Ar}), 7.87(\mathrm{~d}, 1 \mathrm{H}, J=$ $2.1 \mathrm{~Hz}, \mathrm{CH} \mathrm{Ar}) ;{ }^{13} \mathrm{C} \mathrm{NMR}\left(\mathrm{CDCl}_{3}\right) \delta 13.8\left(\mathrm{CH}_{3} \mathrm{CH}_{2}\right), 20.6$ $\left(\mathrm{CH}_{2} \mathrm{CH}_{3}\right), 34.6\left(\mathrm{CH}_{2} \mathrm{CH}\right), 49.8(\mathrm{CH}), 121.4,122.1$, and 125.9 
( $C \mathrm{H} \mathrm{Ar}), 133.1,133.3,152.3$, and $169.2(C \mathrm{Ar}), 172.5(C=\mathrm{O})$. Anal. $\left(\mathrm{C}_{12} \mathrm{H}_{12} \mathrm{ClNO}_{2} \mathrm{~S}_{2}\right) \mathrm{C}, \mathrm{H}, \mathrm{N}$.

2-[(6-Ethoxy-1,3-benzothiazol-2-yl)thio]pentanoic Acid [ rac(12s)]. Yellowish oil, 51\% yield. IR (KBr) $1718 \mathrm{~cm}^{-1} ;{ }^{1} \mathrm{H}$ NMR $\left(\mathrm{CDCl}_{3}\right) \delta 0.95\left(\mathrm{t}, 3 \mathrm{H}, J=7.2 \mathrm{~Hz}, \mathrm{CH}_{3} \mathrm{CH}_{2} \mathrm{CH}_{2}\right), 1.44$ $\left(\mathrm{t}, 3 \mathrm{H}, J=6.9 \mathrm{~Hz}, \mathrm{CH}_{3} \mathrm{CH}_{2} \mathrm{OAr}\right), 1.42-1.57(\mathrm{~m}, 2 \mathrm{H}$, $\left.\mathrm{CH}_{3} \mathrm{CH}_{2} \mathrm{CH}_{2}\right), 1.78-2.20\left(\mathrm{~m}, 2 \mathrm{H}, \mathrm{CH}_{3} \mathrm{CH}_{2} \mathrm{CH}_{2}\right), 4.06$ (q, 2H, $\left.J=6.9 \mathrm{~Hz}, \mathrm{ArOCH}_{2} \mathrm{CH}_{3}\right), 4.17\left(\mathrm{t}, 1 \mathrm{H}, J=7.2 \mathrm{~Hz}, \mathrm{CHCH}_{2}\right)$, $7.04(\mathrm{dd}, 1 \mathrm{H}, J=9.0 \mathrm{~Hz}, J=2.4 \mathrm{~Hz}, \mathrm{CH} \mathrm{Ar}), 7.21(\mathrm{~d}, 1 \mathrm{H}, J=$ $2.4 \mathrm{~Hz}, \mathrm{CH} \mathrm{Ar}), 7.75$ (d, $1 \mathrm{H}, J=9.0 \mathrm{~Hz}, \mathrm{CH} \mathrm{Ar}) ;{ }^{13} \mathrm{C}$ NMR $\left(\mathrm{CDCl}_{3}\right) \delta 13.8\left(\mathrm{CH}_{3} \mathrm{CH}_{2} \mathrm{CH}_{2}\right), 14.9\left(\mathrm{CH}_{3} \mathrm{CH}_{2} \mathrm{OAr}\right), 20.6$ $\left(\mathrm{CH}_{2} \mathrm{CH}_{2} \mathrm{CH}_{3}\right), 32.4\left(\mathrm{CH}_{2} \mathrm{CH}_{2} \mathrm{CH}_{3}\right), \quad 50.1\left(\mathrm{CHCH}_{2}\right), 64.4$ $\left(\mathrm{ArOCH} \mathrm{CH}_{3}\right), 105.0,116.4$, and $121.8(\mathrm{CH} \mathrm{Ar}), 136.4,145.6$, 157.4, and $164.8(C \mathrm{Ar}), 172.2(C=\mathrm{O})$. Anal. $\left(\mathrm{C}_{14} \mathrm{H}_{17} \mathrm{NO}_{3} \mathrm{~S}_{2}\right)$ $\mathrm{C}, \mathrm{H}, \mathrm{N}$.

2-[(5-Chloro-1,3-benzothiazol-2-yl)thio]octanoic Acid [rac(12t)]. White solid, 53\% yield, mp 91-93 ${ }^{\circ} \mathrm{C}$. IR (KBr) 1716 $\mathrm{cm}^{-1} ;{ }^{1} \mathrm{H}$ NMR $\left(\mathrm{CDCl}_{3}\right) \delta 0.86\left(\mathrm{t}, 3 \mathrm{H}, J=7.2 \mathrm{~Hz}, \mathrm{CH}_{3} \mathrm{CH}_{2}\right)$, $1.24-1.29\left(\mathrm{~m}, 6 \mathrm{H}, \mathrm{CH}_{2}\right), 1.42-1.59\left(\mathrm{~m}, 2 \mathrm{H}, \mathrm{CH}_{2}\right), 1.92-2.05(\mathrm{~m}$, $\left.2 \mathrm{H}, \mathrm{CH}_{2}\right), 4.28(\mathrm{t}, 1 \mathrm{H}, J=7.2 \mathrm{~Hz}, \mathrm{CHS}), 7.36(\mathrm{dd}, 1 \mathrm{H}, J=$ $8.7 \mathrm{~Hz}, J=2.1 \mathrm{~Hz}, \mathrm{CHAr}), 7.70(\mathrm{~d}, 1 \mathrm{H}, J=8.7 \mathrm{~Hz}, \mathrm{CH} \mathrm{Ar}), 7.88$ $(\mathrm{d}, 1 \mathrm{H}, J=2.1 \mathrm{~Hz}, \mathrm{CH} \mathrm{Ar}) ;{ }^{13} \mathrm{C} \mathrm{NMR}\left(\mathrm{CDCl}_{3}\right) \delta 14.2$ $\left(\mathrm{CH}_{3} \mathrm{CH}_{2}\right), 22.7,27.3,29.0,30.5$, and $31.6\left(\mathrm{CH}_{2}\right), 50.2(\mathrm{CH})$, 121.3, 122.2, and $126.0(\mathrm{CH} \mathrm{Ar}), 133.2,133.3,152.1$, and 170.4 ( $C \mathrm{Ar}), 171.7(C=\mathrm{O})$. Anal. $\left(\mathrm{C}_{15} \mathrm{H}_{18} \mathrm{ClNO}_{2} \mathrm{~S}_{2}\right) \mathrm{C}, \mathrm{H}, \mathrm{N}$.

[(5-Chloro-1,3-benzothiazol-2-yl)thio](phenyl)acetic Acid [rac(12u)]. White needles (from cyclohexane), $56 \%$ yield, $\mathrm{mp}$ 186-188 ${ }^{\circ} \mathrm{C}$. IR (KBr) $1707 \mathrm{~cm}^{-1} ;{ }^{1} \mathrm{H}$ NMR (CD $\left.{ }_{3} \mathrm{OD}\right) \delta 5.79$ (s, 1H, CHS), 7.31-7.41 (m, 5H, CH Ar), 7.54 (dd, $1 \mathrm{H}, J=$ $8.4 \mathrm{~Hz}, J=1.8 \mathrm{~Hz}, \mathrm{CH} \mathrm{Ar}), 7.81(\mathrm{~d}, 1 \mathrm{H}, J=8.4 \mathrm{~Hz}, \mathrm{CH} \mathrm{Ar})$, $7.84(\mathrm{~d}, 1 \mathrm{H}, J=1.8 \mathrm{~Hz}, \mathrm{CH} \mathrm{Ar}) ;{ }^{13} \mathrm{C} \mathrm{NMR}\left(\mathrm{CD}_{3} \mathrm{OD}\right) \delta 55.0$ (CHS), 120.9, 122.2, 124.8, 128.4, 128.7, and 128.9 (CH Ar), 132.2, 133.8, 135.0, 153.8, and 167.9 ( $C$ Ar $), 171.2(C=\mathrm{O})$. Anal. $\left(\mathrm{C}_{15} \mathrm{H}_{10} \mathrm{ClNO}_{2} \mathrm{~S}_{2}\right) \mathrm{C}, \mathrm{H}, \mathrm{N}$.

General Procedure for the Preparation of $(R)$ - and $(S)$-Ethyl 2-Bromopropanoate. Absolute $\mathrm{EtOH}(37.16 \mathrm{mmol})$, toluene (31.63 $\mathrm{mmol})$, and concentrated $\mathrm{H}_{2} \mathrm{SO}_{4}(0.265 \mathrm{mmol})$ were added to $(R)$ - or $(S)$-2-bromopropanoic acid $(22.12 \mathrm{mmol}$, $3.39 \mathrm{~g})$ using a Dean-Stark apparatus. After the mixture was stirred for $5 \mathrm{~h}$ at reflux, absolute EtOH $(6.64 \mathrm{mmol})$ was added and the reaction mixture was stirred for another $30 \mathrm{~min}$, then poured into water $(10 \mathrm{~mL})$ and extracted with ethyl acetate $(3 \times$ $20 \mathrm{~mL})$. The organic layer was washed with $\mathrm{NaHCO}_{3}(50 \mathrm{~mL})$ and $\mathrm{H}_{2} \mathrm{O}(50 \mathrm{~mL})$, dried over $\mathrm{Na}_{2} \mathrm{SO}_{4}$, and concentrated under reduced pressure. The crude products were used without purification.

General Procedure for the Preparation of Arylthioisobutanoic Esters $(R)$ - and $(S)-111$ and $(R)$ - and $(S)$-110. The heterocyclic thiol $10 \mathrm{l}$ or $100(2.21 \mathrm{mmol})$ and $(R)$ - or $(S)$-ethyl 2-bromopropanoate $(2.21 \mathrm{mmol})$ dissolved in absolute EtOH $(10 \mathrm{~mL})$ were added to a solution of sodium $(50.8 \mathrm{mg}, 2.21 \mathrm{mmol})$ in absolute $\mathrm{EtOH}(5 \mathrm{~mL})$ under nitrogen atmosphere. After the mixture was stirred for $2 \mathrm{~h}$ at reflux, the solvent was removed under reduced pressure. The residue was poured into water $(20 \mathrm{~mL})$ and extracted with diethyl ether $(3 \times 20 \mathrm{~mL})$. The organic layer was dried over $\mathrm{Na}_{2} \mathrm{SO}_{4}$ and concentrated under reduced pressure. The crude products were used without purification.

$(R)$-Ethyl 2-[(5-Chloro-1,3-benzothiazol-2-yl)thio]propanoate $[(\boldsymbol{R})-(\mathbf{1 1 1})]$. Yellowish oil, $80 \%$ yield, $[\alpha]_{\mathrm{D}}^{20}+118.7^{\circ}\left(c 1.01, \mathrm{CHCl}_{3}\right)$. IR $(\mathrm{KBr}) 1735 \mathrm{~cm}^{-1} ;{ }^{1} \mathrm{H}$ NMR $\left(\mathrm{CDCl}_{3}\right) \delta 1.27(\mathrm{t}, 3 \mathrm{H}, J=7.2 \mathrm{~Hz}$, $\left.\mathrm{CH}_{3} \mathrm{CH}_{2}\right), 1.72\left(\mathrm{~d}, 3 \mathrm{H}, J=7.5 \mathrm{~Hz}, \mathrm{CH}_{3} \mathrm{CH}\right), 4.20(\mathrm{q}, 2 \mathrm{H}, J=$ $7.2 \mathrm{~Hz}, \mathrm{CH}_{2} \mathrm{CH}_{3}$ ), 4.69 (q, $1 \mathrm{H}, J=7.5 \mathrm{~Hz}, \mathrm{CH}_{3} \mathrm{CH}$ ), 7.27-7.30 $(\mathrm{dd}, 1 \mathrm{H}, J=8.4 \mathrm{~Hz}, J=1.8 \mathrm{~Hz}, \mathrm{CH} \mathrm{Ar}), 7.67(\mathrm{~d}, 1 \mathrm{H}, J=8.4 \mathrm{~Hz}$, $\mathrm{CHAr}), 7.84(\mathrm{~d}, 1 \mathrm{H}, J=1.8 \mathrm{~Hz}, \mathrm{CHAr}) ;{ }^{13} \mathrm{CNMR}\left(\mathrm{CDCl}_{3}\right) \delta 14.3$ $\left(\mathrm{CH}_{3} \mathrm{CH}_{2}\right), 18.1\left(\mathrm{CH}_{3} \mathrm{CH}\right), 45.4\left(\mathrm{CH}_{3} \mathrm{CH}\right), 62.1\left(\mathrm{CH}_{2} \mathrm{CH}_{3}\right), 121.8$, 121.9, and $125.1(\mathrm{CH} \mathrm{Ar}), 132.4(\mathrm{CCl}), 133.9$ and $154.0(\mathrm{C} \mathrm{Ar})$, $166.9(=C-\mathrm{S}), 171.7(C=\mathrm{O})$. Anal. $\left(\mathrm{C}_{12} \mathrm{H}_{12} \mathrm{ClNO}_{2} \mathrm{~S}_{2}\right) \mathrm{C}, \mathrm{H}, \mathrm{N}$

(S)-Ethyl 2-[(5-Chloro-1,3-benzothiazol-2-yl)thio]propanoate $[(\boldsymbol{S})-(\mathbf{1 1 I})]$. Yellowish oil, $61 \%$ yield, $[\alpha]_{\mathrm{D}}^{24}-107.6^{\circ}\left(c 1.05, \mathrm{CHCl}_{3}\right)$. Spectroscopic data are the same as for the $(R)$-enantiomer.
(R)-Ethyl 2-[(5-methoxy-1,3-benzothiazol-2-yl)thio]propanoate $[(\boldsymbol{R})-(\mathbf{1 1 0})]$. White oil, $57 \%$ yield, $[\alpha]_{\mathrm{D}}^{21}+98.7^{\circ}\left(c 1.68, \mathrm{CHCl}_{3}\right) . \mathrm{IR}$ (KBr) $1732 \mathrm{~cm}^{-1} ;{ }^{1} \mathrm{H}$ NMR $\left(\mathrm{CDCl}_{3}\right) \delta 1.25(\mathrm{t}, 3 \mathrm{H}, J=6.9 \mathrm{~Hz}$, $\left.\mathrm{CH}_{3} \mathrm{CH}_{2}\right), 1.70\left(\mathrm{~d}, 3 \mathrm{H}, J=7.2, \mathrm{CH}_{3} \mathrm{CH}\right), 3.86\left(\mathrm{~s}, 3 \mathrm{H}, \mathrm{OCH}_{3}\right)$, $4.21\left(\mathrm{q}, 2 \mathrm{H}, J=6.9 \mathrm{~Hz}, \mathrm{CH}_{2} \mathrm{CH}_{3}\right), 4.64(\mathrm{q}, 1 \mathrm{H}, J=7.2 \mathrm{~Hz}$, $\left.\mathrm{CH}_{3} \mathrm{CH}\right), 6.96-6.97(\mathrm{dd}, 1 \mathrm{H}, J=8.7 \mathrm{~Hz}, J=2.4 \mathrm{~Hz}, \mathrm{CH} \mathrm{Ar})$, $7.38(\mathrm{~d}, 1 \mathrm{H}, J=8.7 \mathrm{~Hz}, \mathrm{CHAr}), 7.60(\mathrm{~d}, 1 \mathrm{H}, J=2.4 \mathrm{~Hz}, \mathrm{CHAr})$; ${ }^{13} \mathrm{C}$ NMR $\left(\mathrm{CDCl}_{3}\right) \delta 14.3\left(\mathrm{CH}_{3} \mathrm{CH}_{2}\right), 18.2\left(\mathrm{CH}_{3} \mathrm{CH}\right), 45.4$ $\left(\mathrm{CH}_{3} \mathrm{CH}\right), 55.8\left(\mathrm{OCH}_{3}\right), 62.0\left(\mathrm{CH}_{2} \mathrm{CH}_{3}\right), 104.9,114.6$, and 121.4 ( $C \mathrm{H} \mathrm{Ar}), 127.4,154.4$, and 159.1 ( $C \mathrm{Ar}), 165.5(=C-\mathrm{S})$, $171.9(C=\mathrm{O})$. Anal. $\left(\mathrm{C}_{13} \mathrm{H}_{15} \mathrm{NO}_{3} \mathrm{~S}_{2}\right) \mathrm{C}, \mathrm{H}, \mathrm{N}$.

(S)-Ethyl 2-[(5-Methoxy-1,3-benzothiazol-2-yl)thio]propanoate $[(\boldsymbol{S})-(\mathbf{1 1 0})]$. White oil, $60 \%$ yield, $[\alpha]_{\mathrm{D}}^{21}-100.7^{\circ}\left(c 1.68, \mathrm{CHCl}_{3}\right)$. Spectroscopic data are the same as for the $(R)$-enantiomer.

General Procedure for the Preparation of Acids $(R)$ - and $(S)$-12l and $(\boldsymbol{R})$ - and $(\boldsymbol{S})-\mathbf{1 2 0}$. $\mathrm{HCl}(6 \mathrm{~N}, 23 \mathrm{mmol})$ was added to chiral esters $(R)$ - and $(S)$-11l and $(R)$ - and $(S)$-11o $(1.22 \mathrm{mmol}, 367.4 \mathrm{mg})$ at room temperature. Then the mixture was heated at $60{ }^{\circ} \mathrm{C}$ for $24 \mathrm{~h}$. Water $(10 \mathrm{~mL})$ was added to the reaction mixture and then was extracted with diethyl ether $(3 \times 15 \mathrm{~mL})$. The organic layer was dried over $\mathrm{Na}_{2} \mathrm{SO}_{4}$ and concentrated under reduced pressure. The residue was purified by column chromatography on silica gel (eluent, $100 \%$ dichloromethane), affording acids with good yields.

$(\boldsymbol{R})$-2-[(5-Chloro-1,3-benzothiazol-2-yl)thio]propanoic Acid $[(\boldsymbol{R})$ (12I)]. White solid, $87 \%$ yield, $[\alpha]_{\mathrm{D}}^{19}+28.7(c 0.75, \mathrm{MeOH}), \mathrm{mp}$ $108-110{ }^{\circ} \mathrm{C}$. IR (KBr) $1709 \mathrm{~cm}^{-1} ;{ }^{1} \mathrm{H}$ NMR $\left(\mathrm{CD}_{3} \mathrm{OD}\right) \delta 0.16$ $\left(\mathrm{d}, 3 \mathrm{H}, J=6.9 \mathrm{~Hz}, \mathrm{CH}_{3} \mathrm{CH}\right), 3.02\left(\mathrm{q}, 1 \mathrm{H}, J=6.9 \mathrm{~Hz}, \mathrm{CH}_{3} \mathrm{CH}\right)$, $5.73-5.76(\mathrm{dd}, 1 \mathrm{H}, J=8.7 \mathrm{~Hz}, J=1.8 \mathrm{~Hz}, \mathrm{CH} \mathrm{Ar}), 6.22(\mathrm{~d}, 1 \mathrm{H}$, $J=1.8 \mathrm{~Hz}, \mathrm{CH} \mathrm{Ar}), 6.25(\mathrm{~d}, 1 \mathrm{H}, J=8.7 \mathrm{~Hz}, \mathrm{CH} \mathrm{Ar}) ;{ }^{13} \mathrm{C} \mathrm{NMR}$ $\left(\mathrm{CD}_{3} \mathrm{OD}\right) \delta 20.8\left(\mathrm{CH}_{3} \mathrm{CH}\right), 51.1\left(\mathrm{CH}_{3} \mathrm{CH}\right), 121.0,123.6$, and $124.8(\mathrm{CH} \mathrm{Ar}), 131.6$ and $154.5(C \mathrm{Ar}), 133.9(\mathrm{CCl}), 171.4$ $(=C-\mathrm{S}), 173.4(C=\mathrm{O})$. Anal. $\left(\mathrm{C}_{10} \mathrm{H}_{8} \mathrm{ClNO}_{2} \mathrm{~S}_{2}\right) \mathrm{C}, \mathrm{H}, \mathrm{N}$.

(S)-2-[(5-Chloro-1,3-benzothiazol-2-yl)thio]propanoic Acid [(S)(12I)]. White solid, $48 \%$ yield, $[\alpha]_{\mathrm{D}}^{31}-34.9^{\circ}$ (c $\left.0.75, \mathrm{MeOH}\right)$. Spectroscopic data are the same for the $(R)$-enantiomer.

$(R)-2$-[(5-Methoxy-1,3-benzothiazol-2-yl)thio]propanoic Acid $[(\boldsymbol{R})-(\mathbf{1 2 0})]$. White solid, 93\% yield, $[\alpha]_{\mathrm{D}}^{24}+17.8^{\circ}(c 1.05, \mathrm{MeOH})$, mp 134-135 ${ }^{\circ} \mathrm{C}$. IR $(\mathrm{KBr}) 1710 \mathrm{~cm}^{-1} ;{ }^{1} \mathrm{H}$ NMR $\left(\mathrm{CD}_{3} \mathrm{OD}\right) \delta$ $1.70\left(\mathrm{~d}, 3 \mathrm{H}, J=7.5 \mathrm{~Hz}, \mathrm{CH}_{3} \mathrm{CH}\right), 3.84\left(\mathrm{~s}, 3 \mathrm{H}, \mathrm{OCH}_{3}\right), 4.48$ (q, $\left.1 \mathrm{H}, J=7.5 \mathrm{~Hz}, \mathrm{CH}_{3} \mathrm{CH}\right), 6.93-6.97(\mathrm{dd}, 1 \mathrm{H}, J=8.7 \mathrm{~Hz}, J=$ $2.4 \mathrm{~Hz}, \mathrm{CH} \mathrm{Ar}$ ), 7.33 (d, $1 \mathrm{H}, J=2.4 \mathrm{~Hz}, \mathrm{CH} \mathrm{Ar}), 7.67$ (d, $1 \mathrm{H}$, $J=8.7 \mathrm{~Hz}, \mathrm{CH} \mathrm{Ar}) ;{ }^{13} \mathrm{C} \mathrm{NMR}\left(\mathrm{CD}_{3} \mathrm{OD}\right) \delta 18.9\left(\mathrm{CH}_{3} \mathrm{CH}\right), 49.3$ $\left(\mathrm{CH}_{3} \mathrm{CH}\right), 54.8\left(\mathrm{OCH}_{3}\right), 104.0,113.8$, and $121.2(\mathrm{CH} \mathrm{Ar}), 126.6$, 154.4, and $159.4(C \mathrm{Ar}), 155.8(=C-\mathrm{S}), 168.9(C=\mathrm{O})$. Anal. $\left(\mathrm{C}_{11} \mathrm{H}_{11} \mathrm{NO}_{3} \mathrm{~S}_{2}\right) \mathrm{C}, \mathrm{H}, \mathrm{N}$.

(S)-2-[(5-Methoxy-1,3-benzothiazol-2-yl)thio]propanoic Acid $[(\boldsymbol{S})-(\mathbf{1 2 0})]$. White solid, $85 \%$ yield, $[\alpha]_{\mathrm{D}}^{24}-17.3^{\circ}(c 0.79, \mathrm{MeOH})$, mp $134-135^{\circ} \mathrm{C}$. IR (KBr) $1710 \mathrm{~cm}^{-1} ;{ }^{1} \mathrm{H} \mathrm{NMR}\left(\mathrm{CD}_{3} \mathrm{OD}\right) \delta$ $1.70\left(\mathrm{~d}, 3 \mathrm{H}, J=7.5 \mathrm{~Hz}, \mathrm{CH}_{3} \mathrm{CH}\right), 3.84\left(\mathrm{~s}, 3 \mathrm{H}, \mathrm{OCH}_{3}\right), 4.48(\mathrm{q}$, $\left.1 \mathrm{H}, J=7.5 \mathrm{~Hz}, \mathrm{CH}_{3} \mathrm{CH}\right), 6.93-6.97(\mathrm{dd}, 1 \mathrm{H}, J=8.7 \mathrm{~Hz}, J=$ $2.4 \mathrm{~Hz}, \mathrm{CH} \mathrm{Ar}$ ), 7.33 (d, $1 \mathrm{H}, J=2.4 \mathrm{~Hz}, \mathrm{CH} \mathrm{Ar}), 7.67$ (d, $1 \mathrm{H}$, $J=8.7 \mathrm{~Hz}, \mathrm{CH} \mathrm{Ar}) ;{ }^{13} \mathrm{C} \mathrm{NMR}\left(\mathrm{CD}_{3} \mathrm{OD}\right) \delta 18.9\left(\mathrm{CH}_{3} \mathrm{CH}\right), 49.3$ $\left(\mathrm{CH}_{3} \mathrm{CH}\right), 54.8\left(\mathrm{OCH}_{3}\right), 104.0,113.8$, and $121.2(\mathrm{CH} \mathrm{Ar}), 126.6$, 154.4, and $159.4(C \mathrm{Ar}), 155.8(=C-\mathrm{S}), 168.9(C=\mathrm{O})$. Anal. $\left(\mathrm{C}_{11} \mathrm{H}_{11} \mathrm{NO}_{3} \mathrm{~S}_{2}\right) \mathrm{C}, \mathrm{H}, \mathrm{N}$.

Biology. Cell-Based Transactivation Assay. Human embryonic kidney 293 cell line (HEK293) was cultured in Dulbecco's modified Eagle's minimal essential medium containing $10 \%$ fetal calf serum and supplemented with penicillin/streptomycin, sodium pyruvate, and nonessential amino acids at $37^{\circ} \mathrm{C}$ in a humidified atmosphere of $5 \% \mathrm{CO}_{2}$ in air. Ligand agonist activity for each PPAR subtype was determined by its transactivation activity in a cell-based reporter-gene assay. Transfections of PPAR and reporter gene constructs were performed by calcium phosphate coprecipitation. Before transfection, the culture medium was replaced by fresh serum-free medium, and $6 \mathrm{~h}$ after transfection, the ligand, dissolved in DMSO, was added. The final concentration of DMSO did not exceed $0.1 \%(\mathrm{v} / \mathrm{v})$ in any of the samples. Eighteen hours after treatment, luciferase and renilla activities were measured by a dual luciferase assay kit 
(Promega) using a luminometer (Labsystems Ascent Luminoskan reader). DNA cotransfection experiments included $50 \mathrm{ng}$ of reporter plasmid, $20 \mathrm{ng}$ of renilla, $40 \mathrm{ng}$ of pGEM, and $30 \mathrm{ng}$ of each receptor expression plasmid per well in a 96-well plate. Luciferase data were normalized to the internal renilla control, and reported values are the mean of triplicate assays. Luciferase activity was determined as fold activation relative to untreated cells.

RTqPCR. HepG2 was obtained from ATCC (ATCC-LGC Promochem, London, U.K.). Cells were maintained in Dulbecco's modified Eagle's medium supplemented with 10\% FBSGOLD and $1 \%$ penicillin/streptomycin at $37^{\circ} \mathrm{C}$ in a humidified incubator with $5 \% \mathrm{CO}_{2}$ in air. For the treatment, $1 \times 10^{6}$ cells were seeded into six-well culture dishes, grown for $24 \mathrm{~h}$, and finally treated with vehicle (DMSO) and ligand $(150 \mu \mathrm{M})$. After incubation for $48 \mathrm{~h}$, mRNA was extracted.

Total RNA was isolated by TRIzol reagent (Invitrogen, Carlsbad, CA) following the manufacture's instruction. To avoid possible DNA contaminations, RNA was treated with DNAase-1 (Ambion, Foster City, CA). RNA purity was checked by spectrophotometer and RNA integrity by examination on agarose gel electrophoresis. cDNA was synthesized retrotranscribing $4 \mu \mathrm{g}$ of total RNA in a total volume of $100 \mu \mathrm{L}$ using a high capacity DNA archive kit (Applied Biosystem, Foster City, CA) and following the manufacturer's instruction.

RTqPCR primers were designed using Primer Express software. RTqPCR assays were performed in 96-well optical reaction plates using the ABI 7500HT machine (Applied Biosystem). PCR assays were conducted in triplicate wells for each sample. Baseline values of amplification plots were set automatically, and threshold values were kept constant to obtain normalized cycle times and linear regression data. The following reaction mixture per well was used: $10 \mu \mathrm{L}$ Power Syber Green (Applied Biosystem), $2.4 \mu \mathrm{L}$ of primers at a final concentration of $150 \mathrm{nM}, 4.6 \mu \mathrm{L}$ of RNAase free water, $3 \mu \mathrm{L}$ of cDNA (60 ng). For all experiments the following conditions were used: denaturation at $95{ }^{\circ} \mathrm{C}$ for $10 \mathrm{~min}$, followed by 40 cycles at $95^{\circ} \mathrm{C}$ for $15 \mathrm{~s}$, then at $60{ }^{\circ} \mathrm{C}$ for $60 \mathrm{~s}$. Quantitative normalization of cDNA in each sample was performed using cyclophilin as internal control. Relative quantification was performed using the $\Delta \Delta C T$ method.

Validated primers for RTqPCR are listed below:

Human CPT1: FW-5'TGCCATGGATCTGCTGTATATCC3', RV-5'GCGTTGCCGGCTCTTG3

Human cyclophilin: FW-5'TTTCATCTGCACTGCCAAGA3', RV-5'TTGCAAAACACCACATGCT $3^{\prime}$

Acknowledgment. The authors gratefully acknowledge the Italian MIUR for financial support and Dr. David J. Mangeldorf (Dallas, TX) for the PPAR plasmids. They also thank Maria Luisa Tricca for her precious technical help. Dr. Antonio Moschetta is funded by Italian Association for Cancer Research (AIRC, Milan, Italy), European Research Council Starting Independent Grant IDEAS 2008, European Community's Seventh Framework Programme FP7/2007-2013 under Grant Agreement No. 202272 (LipidomicNet), Italian Ministry of Health and Education (Finanziamenti per la Ricerca di Base), Cariplo Fundation Milan, Telethon Fundation (Grant GGP08259). Dr. Michele Petruzzelli is supported by the RosarioSamanin Fund, and Dr. Annalisa Morgano is a fellow of the G. d'Annunzio Oncology Program (Chieti, Italy).

\section{References}

(1) (a) Issemann, I.; Green, S. Activation of a member of the steroid hormone receptor superfamily by peroxisome proliferators. Nature 1990, 347, 645-650. (b) Motojima, K. Peroxisome proliferator-activated receptor (PPAR): structure, mechanisms of activation and diverse functions. Cell Struct. Funct. 1993, 18, 267-277. (c) Zoete, V.; Grosdidier, A.; Michielin, O. Peroxisome proliferator-activated receptor structures: ligand specificity, molecular switch and interactions with regulators. Biochim. Biophys. Acta 2007, 1771, 915-925. (d) Vanden Heuvel, J. P. The PPAR resource page. Biochim. Biophys. Acta 2007, $1771,1108-1112$

(2) (a) Berger, J.; Moller, D. E. The mechanisms of action of PPARs. Annu. Rev. Med. 2002, 53, 409-435. (b) Kota, B. P.; Huang, T. H-W.; Roufogalis, B. D. An overview on biological mechanisms of PPARs. Pharmacol. Res. 2005, 51, 85-94. (c) Feige, J. N.; Gelman, L.; Michalik, L.; Desvergne, B.; Wahli, W. From molecular action to physiological outputs: peroxisome proliferator-activated receptors are nuclear receptors at the crossroads of key cellular functions. Prog. Lipid Res. 2006, 45, 120-159.

(3) (a) Forman, B. M.; Chen, J.; Evans, R. M. Hypolipidemic drugs, polyunsaturated fatty acids, and eicosanoids are ligands for peroxisome proliferator-activated receptors $\alpha$ and $\boldsymbol{\delta}$. Proc. Natl. Acad. Sci. U.S.A. 1997, 94, 4312-4317. (b) Kliewer, S. A.; Sundseth, S. S.; Jones, S. A.; Brown, P. J.; Bruce Wisely, G.; Koble, C. S.; Devchand, P.; Wahli, W.; Willson, T. M.; Lenhard, J. M.; Lehmann, J. M. Fatty acids and eicosanoids regulate gene expression through direct interactions with peroxisome proliferator-activated receptors $\alpha$ and $\gamma$. Proc. Natl. Acad. Sci. U.S.A. 1997, 94, 4318-4323. (c) Bishop-Bailey, D.; Wray, J. Peroxisome proliferator-activated receptors: a critical review on endogenous pathways for ligand generation. Prostaglandins Other Lipid Mediators 2003, 71, 1-22. (d) Grimaldi, P. A. Peroxisome proliferator-activated receptors as sensors of fatty acids and derivatives. Cell. Mol. Life Sci. 2007, 64, 2459-2464.

(4) (a) van Raalte, D. H.; Li, M.; Pritchard, P. H.; Wasan, K. M. Peroxisome proliferator-activated receptor (PPAR)- $\alpha$ : a pharmacological target with a promising future. Pharm. Res. 2004, 21, 1531. (b) Lefebvre, P.; Chinetti, G.; Fruchart, J. C.; Bart Staels, B. Sorting out the roles of PPAR $\alpha$ in energy metabolism and vascular homeostasis. J. Clin. Invest. 2006, 116, 571-580.

(5) (a) Gouni-Berthold, I.; Krone, W. Peroxisome proliferator-activated receptor $\alpha(\operatorname{PPAR} \alpha)$ and atherosclerosis. Curr. Drug Targets: Cardiovasc. Haematol. Disord. 2005, 5, 513-525. (b) IsraelianKonaraki, Z.; Reaven, P. D. Peroxisome proliferator-activated receptor-alpha and atherosclerosis: from basic mechanisms to clinical implications. Cardiol. Rev. 2005, 13, 240-246. (c) Duval, C.; Muller, M.; Kersten, S. PPAR $\alpha$ and dyslipidemia. Biochim. Biophys. Acta 2007, 1771, 961-971. (d) Zandbergen, F.; Plutzky, J. PPAR $\alpha$ in atherosclerosis and inflammation. Biochim. Biophys. Acta, Mol. Cell Biol. Lipids 2007, 1771, 972-982. (e) Cheng, A. Y. Y.; Leiter, L. A. PPAR- $\alpha$ : therapeutic role in diabetes-related cardiovascular disease. Diabetes, Obes. Metab. 2008, 9, 691-698.

(6) (a) Miyachi, H. Synthetic ligands for peroxisome proliferatoractivated receptor- $\alpha$, review of the patent literature 2000-2003. Expert Opin. Ther. Pat. 2004, 14, 607-618. (b) Balakumar, P.; Rose, M.; Singh, M. PPAR ligands: are they potential agents for cardiovascular disorders? Pharmacology 2007, 80, 1-10. (c) Fruchart, J. C. Novel peroxisome proliferator activated receptor- $\alpha$ agonists. Am. J. Cardiol. 2007, 100, 41-46.

(7) (a) Schoonjans, K.; Staels, B. M; Auwerx, J. Role of the peroxisome proliferator-activated receptor (PPAR) in mediating the effects of fibrates and fatty acids on gene expression. J. Lipid Res. 1996, 37, 907-925. (b) Staels, B.; Auwerx, J. Role of PPAR in the pharmacological regulation of lipoprotein metabolism by fibrates and thiazolidinediones. Curr. Pharm. Des. 1997, 3, 1-14. (c) Fruchart, J. C.; Duriez, P.; Staels, B. Molecular mechanism of action of the fibrates. J. Soc. Biol. 1999, 193, 67-75. (d) Chapman, M. J. Fibrates in 2003: therapeutic action in atherogenic dyslipidaemia and future perspectives. Atherosclerosis 2003, 171, 1-13. (e) Chinetti-Gbaguidi, G.; Fruchart, J. C.; Staels, B. Pleiotropic effects of fibrates. Curr. Atheroscler. Rep. 2005, 7, 396-401. (f) Barter, P. J.; Rye, K.-A. Is there a role for fibrates in the management of dyslipidemia in the metabolic syndrome? Arterioscler., Thromb., Vasc. Biol. 2008, 28, 39-46. (g) Staels, B.; Maes, M.; Zambon, A. Fibrates and future PPAR $\alpha$ agonists in the treatment of cardiovascular disease. Nat. Clin. Pract. Cardiovasc. Med. 2008, 5, $542-553$.

(8) Brown, P. J.; Stuart, L. W.; Hurley, K. P.; Lewis, M. C.; Winegar, D. A.; Wilson, J. G.; Wilkison, W. O.; Ittoop, O. R.; Willson, T. M. Identification of a subtype selective human PPAR agonist through parallel-array synthesis. Bioorg. Med. Chem. Lett. 2001, 11, 12251227.

(9) (a) Nomura, M.; Tanase, T.; Ide, T.; Tsunoda, M.; Suzuki, M.; Uchiki, H.; Murakami, K.; Miyachi, H. Design, synthesis and evaluation of substituted phenylpropanoic acid derivatives as human peroxisome proliferator activated receptor activators. Discovery of potent and human peroxisome proliferator activated receptor $\alpha$ subtype-selective activators. J. Med. Chem. 2003, 46, 3581-3599. (b) Miyachi, H.; Uchiki, H. Bioorg. Med. Chem. Lett. 2003, 13, 3145-3149.

(10) Xu, Y.; Mayhugh, D.; Saeed, A.; Wang, X.; Thompson, R. C.; Dominianni, S. J.; Kauffman, R. F.; Singh, J.; Bean, J. S.; Bensch, 
W. R.; Barr, R. W.; Osborne, J.; Montrose-Rafizadeh, C.; Zink, R. W.; Yumibe, N. P.; Huang, N.; Luffer-Atlas, D.; Rungta, D.; Maise, D. E.; Mantlo, N. B. Design and synthesis of a potent and selective triazolone-based peroxisome proliferator-activated receptor $\alpha$ agonist. J. Med. Chem. 2003, 46, 5121-5124.

(11) Shi, G. Q.; Dropinski, J. F.; Zhang, Y.; Santini, C.; Sahoo, S. P.; Berger, J. P.; MacNaul, K. L.; Zhou, G.; Agrawal, A.; Alvaro, R.; Cai, T-q.; Hernandez, M.; Wright, S. D.; Moller, D. E.; Heck, J. V.; Meinke, P. T. Novel 2,3-dihydrobenzofuran-2-carboxylic acids: highly potent and subtype-selective PPAR $\alpha$ agonists with potent hypolipidemic activity. J. Med. Chem. 2005, 48, 5589-5599.

(12) Matthews, J. M.; Chen, X.; Cryan, E.; Hlasta, D. J.; Rybczynski, P. J.; Strauss, K.; Tang, Y.; Xu, June, Z.; Yang, M.; Zhou, L.; Demarest, K. T. Design and synthesis of indane-ureido-thioisobutyric acids: a novel class of PPAR $\alpha$ agonists. Bioorg. Med. Chem. Lett. 2007, 17, 6773-6778.

(13) (a) Asaki, T.; Aoki, T.; Hamamoto, T.; Sugiyama, Y.; Ohmachi, S.; Kuwabara, K.; Murakami, K; Todo, M. Structure-activity studies on 1,3-dioxane-2-carboxylic acid derivatives, a novel class of subtype-selective peroxisome proliferator-activated receptor $\alpha($ PPAR $\alpha)$ agonists. Bioorg. Med. Chem. 2008, 16, 981-994. (b) Aoki, T.; Asaki, T.; Hamamoto, T.; Sugiyama, Y.; Ohmachi, S.; Kuwabara, K.; Murakami, K; Todo, M. Discovery of a novel class of 1,3-dioxane-2-carboxylic acid derivatives as subtype-selective peroxisome proliferator-activated receptor $\alpha(\mathrm{PPAR} \alpha)$ agonists. Bioorg. Med. Chem. Lett. 2008, 18, 2128-2132.

(14) Ammazzalorso, A.; Amoroso, R.; Baraldi, M.; Bettoni, G.; Braghiroli, D.; De Filippis, B.; Giampietro, L.; Tricca, M. L.; Vezzalini, F.
Synthesis and antiplatelet activity of thioaryloxyacids analogues of clofibric acid. Eur. J. Med. Chem. 2005, 40, 918-921.

(15) Zhu, L.; Zhang, M.; Dai, M. A convenient synthesis of 2-mercapto and 2-chlorobenzothiazoles. J. Heterocycl. Chem. 2005, 42, 727-730.

(16) Schulman, I. G.; Heyman, R. A. The flip side: identifying small molecule regulators of nuclear receptors. Chem. Biol. 2004, 11, 639-646.

(17) Rangwala, S. M.; O'Brien, M. L.; Tortorella, V.; Longo, A.; Loiodice, F.; Noonan, D. J.; Feller, D. R. Stereoselective effects of chiral clofibric acid analogs on rat peroxisome proliferatoractivated receptor (rPPAR) activation and peroxisomal fatty acidoxidation. Chirality 1997, 9, 37-47.

(18) Fracchiolla, G; Laghezza, A.; Piemontese, L.; Carbonara, G.; Lavecchia, A.; Tortorella, P.; Crestani, M.; Novellino, E.; Loiodice, F. Synthesis, biological evaluation, and molecular modeling investigation of chiral phenoxyacetic acid analogues with PPAR $\alpha$ and PPAR $\gamma$ agonist activity. ChemMedChem 2007, 14, 641-654.

(19) Miyachi, H.; Nomura, M.; Tanase, T.; Suzuki, M.; Murakami, K.; Awano, K. Enantio-dependent binding and transactivation of optically active phenylpropanoic acid derivatives at human peroxisome proliferator-activated receptor alpha. Bioorg. Med. Chem. Lett. 2002, 12, 333-335.

(20) Lawrence, J. W.; Li, Y.; Chen, S.; De Luca, J. G.; Berger, J. P.; Umbenhauer, D. R.; Moller, D. E.; Zhou, G. Differential gene regulation in human versus rodent hepatocytes by peroxisome proliferator-activated receptor (PPAR) alpha. PPAR alpha fails to induce peroxisome proliferation-associated genes in human cells independently of the level of receptor expression. J. Biol. Chem. 2001, 276, 31521-31527. 